\title{
Large-Scale Analysis of Relationships between Mineral Dust, Ice Cloud Properties, and Precipitation from Satellite Observations Using a Bayesian Approach: Theoretical Basis and First Results for the Tropical Atlantic Ocean
}

\author{
Lars Klüser and Thomas Popp \\ Deutsches Zentrum für Luft- und Raumfahrt e.V. (DLR), Deutsches Fernerkundungsdatenzentrum (DFD), 82334 Wessling, Germany \\ Correspondence should be addressed to Thomas Popp; thomas.popp@dlr.de
}

Received 22 February 2017; Revised 29 May 2017; Accepted 5 June 2017; Published 20 July 2017

Academic Editor: Roberto Fraile

Copyright (C) 2017 Lars Klüser and Thomas Popp. This is an open access article distributed under the Creative Commons Attribution License, which permits unrestricted use, distribution, and reproduction in any medium, provided the original work is properly cited.

\begin{abstract}
Mineral dust and ice cloud observations from the Infrared Atmospheric Sounding Interferometer (IASI) are used to assess the relationships between desert dust aerosols and ice clouds over the tropical Atlantic Ocean during the hurricane season 2008. Cloud property histograms are first adjusted for varying cloud top temperature or ice water path distributions with a Bayesian approach to account for meteorological constraints on the cloud variables. Then, histogram differences between dust load classes are used to describe the impact of dust load on cloud property statistics. The analysis of the histogram differences shows that ice crystal sizes are reduced with increasing aerosol load and ice cloud optical depth and ice water path are increased. The distributions of all three variables broaden and get less skewed in dusty environments. For ice crystal size the significant bimodality is reduced and the order of peaks is reversed. Moreover, it is shown that not only are distributions of ice cloud variables simply shifted linearly but also variance, skewness, and complexity of the cloud variable distributions are significantly affected. This implies that the whole cloud variable distributions have to be considered for indirect aerosol effects in any application for climate modelling.
\end{abstract}

\section{Introduction}

Atmospheric aerosol impacts on cloud microphysical properties and thus can change cloud radiative forcing by socalled "indirect aerosol effects" (e.g., [1-3]). This adds to their direct radiative forcing through reflecting and absorbing solar radiation (e.g., [4]). Furthermore, it has been controversially discussed $[2,4-6]$ whether aerosols can modify precipitation efficiency and thus affect the hydrological cycle. The net effect of aerosols on cloud cover and cloud properties is a combination of several counteracting processes (e.g., [5-7]).

The common basic assumption is that through reducing cloud droplet size aerosols suppress (warm) precipitation $[2,4,7,8]$. However, this can lead to extreme precipitation events later in time or further away $[5,9]$. The magnitude and sign of the various aerosol effects depend on their chemical composition (aerosol type) (e.g., [4, 6]). In particular, mineral dust is reported to be efficient ice nuclei [10]; therefore, indirect effects of dust aerosols include relationships between dust load and ice cloud properties (e.g., [11]). Due to the acting of dust particles as efficient ice nuclei, and consequently a resulting impact on in-cloud microphysics and latent heat release, also the macrophysical properties of clouds may be affected by the presence of desert dust. DeMott et al. [12] describe an interaction resulting in an extensivation of cirrus clouds due to the microphysical effects of desert dust in convective and stratiform clouds. Such an effect on microphysical cloud properties would result in an alteration of indirect dust effects on the radiation balance as well, as cirrus clouds typically show a strong warming longwave effect overweighing the rather small shortwave effect. The analysis of indirect dust effects due to microphysical alterations has 
been shown to be quite hard to quantify due to the ambiguity of reliably determining and defining ice crystal size [13-15]. It is subject to intensive discussion whether the dust effect as efficient ice nuclei impacts on crystal habit as well (which currently cannot be assessed from remote sensing).

Some studies present evidence of convective invigoration due to the presence of dust particles and their acting as ice nuclei (e.g., [16]). Nevertheless Connolly et al. [17] showed with model simulations that there may be no very clear relationships between aerosol entrainment and convective invigoration due to strong nonlinearities in the effects.

An advanced statistical analysis method following a Bayesian approach is applied to large-scale satellite observations, in this example, to observations of mineral dust and ice cloud properties retrieved by the Infrared Mineral Aerosol Retrieval Scheme (IMARS) from the Infrared Atmospheric Sounding Interferometer (IASI). The analysis method requires rather homogeneous meteorological conditions for a significant statistical assessment of cloud development. For this reason, the analysis presented here is confined to summer conditions over the tropical Atlantic Ocean $\left(5^{\circ}-35^{\circ}\right.$ North and $70^{\circ}-10^{\circ}$ West, over ocean only, June-November 2008). This coincides with the Atlantic Ocean hurricane season (e.g., [18]). Moreover, the analysis is based on absolutely consistent observational data; that is, all dust and cloud observations (precipitation estimates being the sole exception) are based on observations with the same instrument and the same method. This approach is seen as favourable in order to exclude statistical problems such as double counting or spurious correlations resulting from methodology rather than observation.

The region and season are characterized by the frequent abundance of mesoscale deep convective cloud systems (under favourable conditions developing into tropical cyclones or even hurricanes) in very close vicinity of the airborne dust.

\section{Data}

2.1. IASI Observations of Mineral Dust and Ice Clouds. The IASI instrument operated on the Metop-A satellite is a Michelson interferometer with very fine spectral resolution at a nadir footprint of approximately $6 \mathrm{~km}$ in the terrestrial infrared spectral range. The IMARS method has been developed for desert dust retrieval from IASI [19-22]. Recently, the retrieval scheme has been updated with more concise optical properties for nonspherical dust particles [23]. Moreover, it has been expanded by an accompanying ice cloud properties retrieval branch which uses exactly the same mathematical approach $[21,22]$. The dust retrieval exploits the vibrational resonance peak of silicate minerals around $10 \mu \mathrm{m}$ typically found in desert dust, which also allows characterization of the mineralogical composition of the aerosol. With this method mineral dust retrieval is possible over ocean, over land (including bright surfaces in visible bands), and even above low-level water clouds $[19,24]$. Being a terrestrial infrared (TIR) method, IMARS is independent of sun light and thus IASI overpasses at day (descending) and night (ascending) can be used to derive desert dust properties, yielding two observations per day in the tropics. The retrieved infrared dust optical depth is converted into visible dust optical depth using the retrieved mineralogical composition and size; all results in this study present dust aerosol optical depth at $0.55 \mu \mathrm{m}$.

As the extinction peak of silicates in the infrared is exploited for this method, the retrieval is sensitive to silicate aerosols (i.e., desert dust) only and provides a powerful method to discriminate the impact of desert dust on clouds from that of other aerosol types. Evaluation of the latest IMARS version used for the analysis is summarized in the appendix. It is evident from this analysis that the performance with respect to dust quantification is much better over ocean than it is over land.

Cloud retrieval exploits the differential extinction in the TIR window analogously to the dust retrieval. The spectral variation of ice extinction provides an opposite signal to that of desert dust and thus ice clouds can be discriminated from desert dust by the information conveyed within the retrieval (i.e., from the a posteriori probabilities for desert dust and ice clouds; see [21]).

All IR methods are limited to infrared optical depth values below $\sim 6-8$ (in units of optical depth) since the high opacity of thick ice clouds saturates the radiance signal for higher optical depth. Consequently, the observed radiance is mainly originating from cloud top emission [25]. Due to this behaviour, one can retrieve ice cloud optical depth and effective diameter simultaneously for sufficiently low optical depth (i.e., not saturating signal). The ice water path can then be deduced from optical depth and effective diameter. As a last step, retrieved cloud optical depth in the infrared is converted into visible wavelengths following the method of Heymsfield et al. [26]. For the remainder of this study, Cloud Optical Depth (COD) always refers to the visible optical depth (i.e., optical depth at $0.55 \mu \mathrm{m}$ ) of ice clouds.

It is important to note that the liquid water fraction of clouds cannot be analysed with this type of method. This is due to the fact that the spectral extinction/emission of liquid water droplets has only little variation in the infrared window. Based on this condition, the IASI retrieval is specifically sensitive to ice clouds, especially in deep convective cloud systems and cirrus clouds. Accordingly, this study deals only with dust effects on ice clouds. Moreover, with the method being completely insensitive to the water fraction of the clouds, a reliable discrimination of ice clouds from liquid water clouds is assured.

Figure 1 presents the observation frequencies of Saharan dust and ice clouds (all detected observations) over the tropical North Atlantic Ocean during the hurricane season 2008, subdivided by daytime (descending overpasses) and nighttime (ascending overpasses). The dust plume extending West from the African coast over the ocean is clearly visible as well as the high cloud cover region of the intertropical convergence zone near the Southern boundary of the domain. Especially for the dust it can be seen that over land, and most prominently over the Sahara desert, the observations show a well expressed diurnal cycle whereas there is hardly 


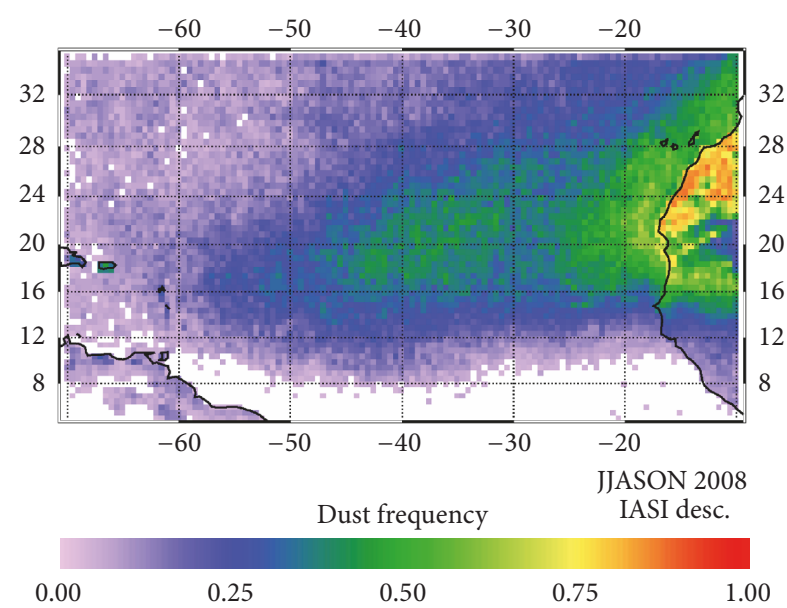

(a)

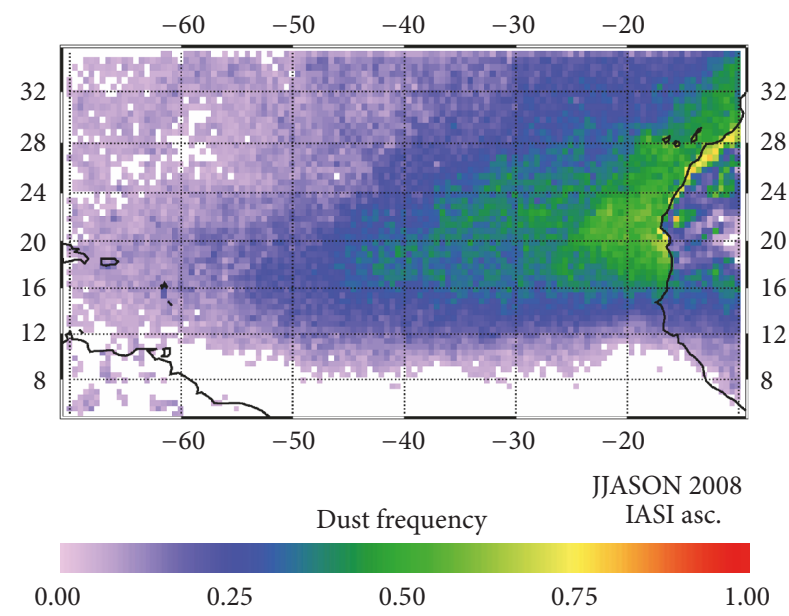

(c)

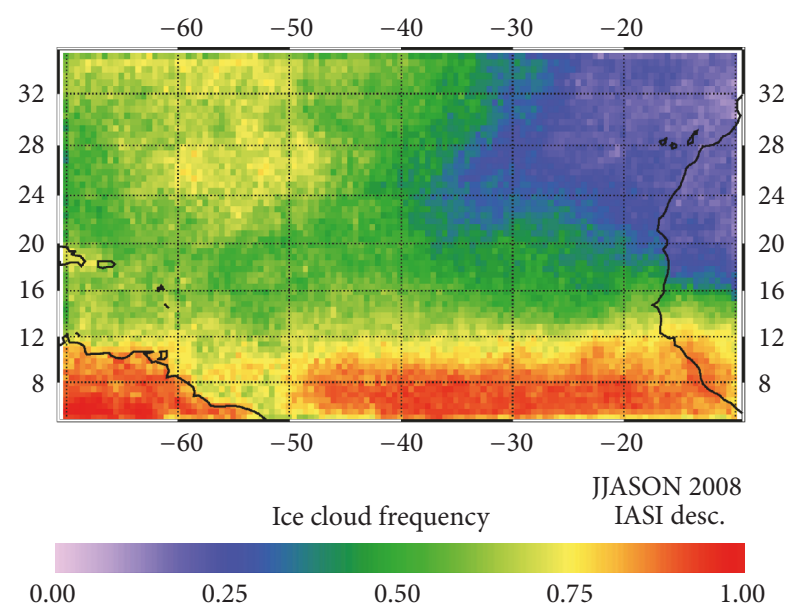

(b)

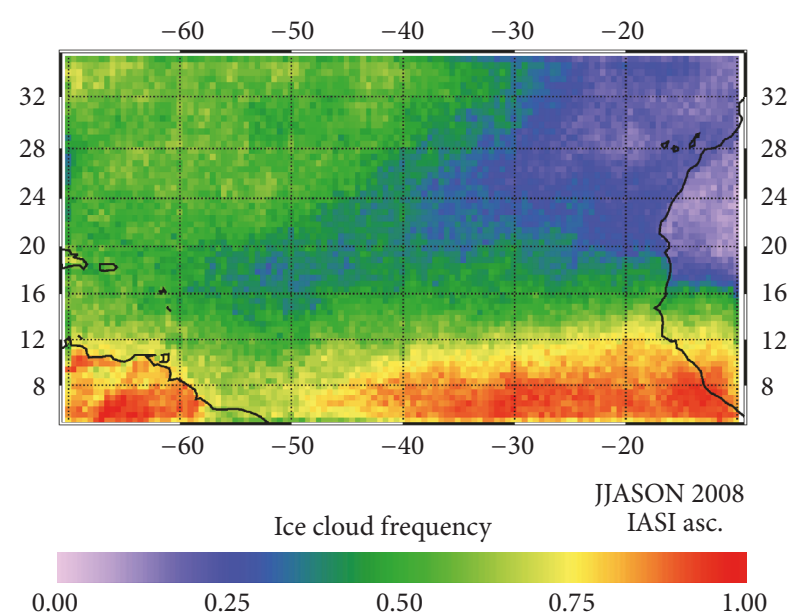

(d)

FIGURE 1: Observation frequency of desert dust $(a, c)$ and ice clouds ( $b, d$ ) obtained from IASI descending (a, b) and ascending (c, d) overpasses with the IMARS retrieval for the hurricane season 2008 over the tropical North Atlantic Ocean.

any diurnal variation in dust activity over the Ocean. Consequently the statistical analysis can be performed without diurnal subsetting over ocean (over land this would not be as well-confounded).

Figure 2 depicts averages of retrieval information content and the number of independent ice cloud variables for the same domain and period. The retrieval information content $I_{\text {ret }}$ is the Shannon Information Content [27] or Shannon Measure of Information [28] of the distinction between ice clouds and desert dust (see $[21,22])$ :

$$
I_{\text {ret }}=-\left(P_{\text {cloud }} \cdot \log _{2}\left(P_{\text {cloud }}\right)+P_{\text {dust }} \cdot \log _{2}\left(P_{\text {dust }}\right)\right) .
$$

The lower the value of $I_{\text {ret }}$, the more reliable the discrimination between dust and cloud. On the other hand $I_{\text {ret }}=1$ describes an equilibrium state between the probabilities for cloud and for dust, $P_{\text {cloud }}$ and $P_{\text {dust }}$ [28], and thus a state where the retrieval algorithm is not capable of discriminating ice cloud from dust [22]. It is evident that especially in the northeastern quadrant of the domain, where both dust and cloud frequency are comparatively low, the retrieval reliability is lowest as $I_{\text {ret }}$ approaches the equilibrium value of 1 . On the other hand, the dust and cloud signals can be well discriminated in the cloud belt of the intertropical convergence zone (ITCZ) and over the Saharan desert.

The number of independent variables for cloud properties $N_{\text {var }}$ is determined within IMARS from the ice cloud probability $\left(P_{\text {cloud }}\right)$ and the intrinsic uncertainty of the ice cloud retrieval $\left(\varepsilon_{\text {cloud }}\right)$ as follows $[22,29]$ :

$$
N_{\text {var }}(\text { cloud })=\sqrt{3} \cdot \log _{2}\left(\frac{P_{\text {cloud }}+\varepsilon_{\text {cloud }}}{\varepsilon_{\text {cloud }}}\right) .
$$

It can be seen that the spatial distribution of $N_{\text {var }}$ (cloud) is rather homogeneous over the ocean throughout the domain with magnitude approximately between 2.0 and 2.5. Only in the northeastern sector, where cloud observation frequency is very low (Figure 1), the number of variables, which can be 


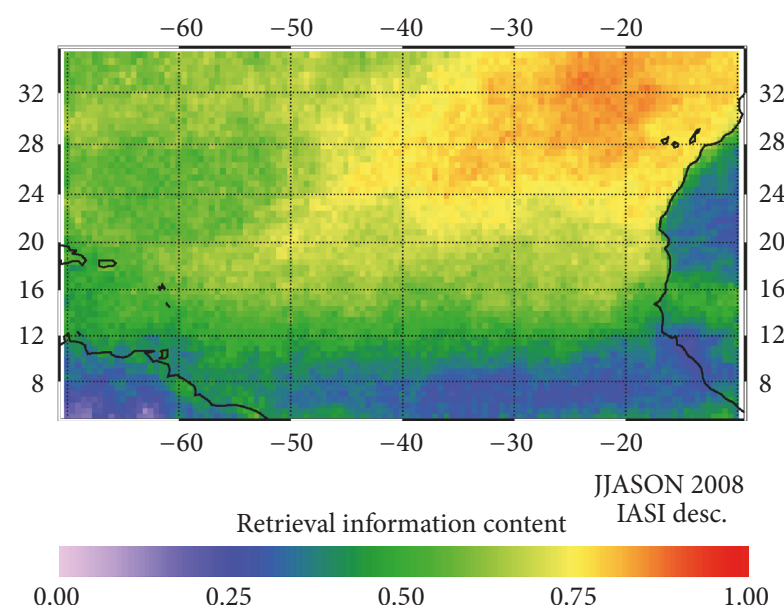

(a)

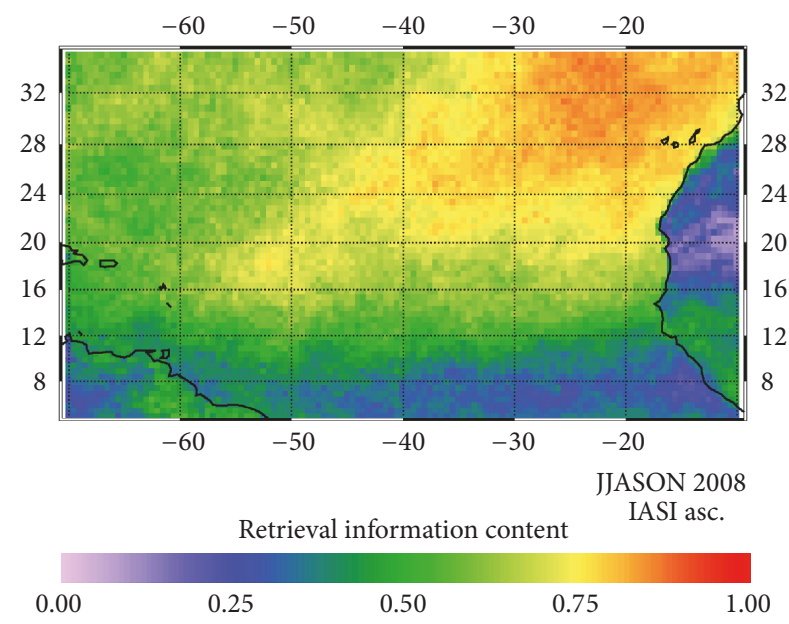

(c)

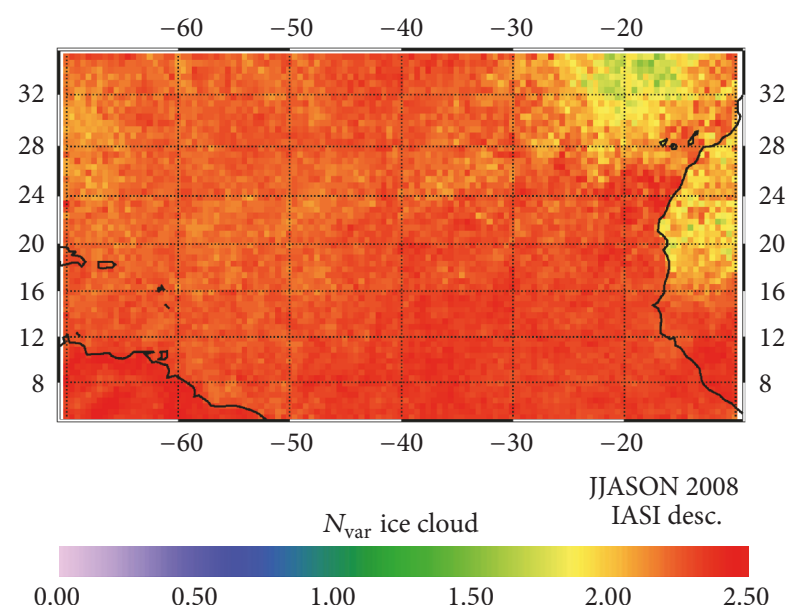

(b)

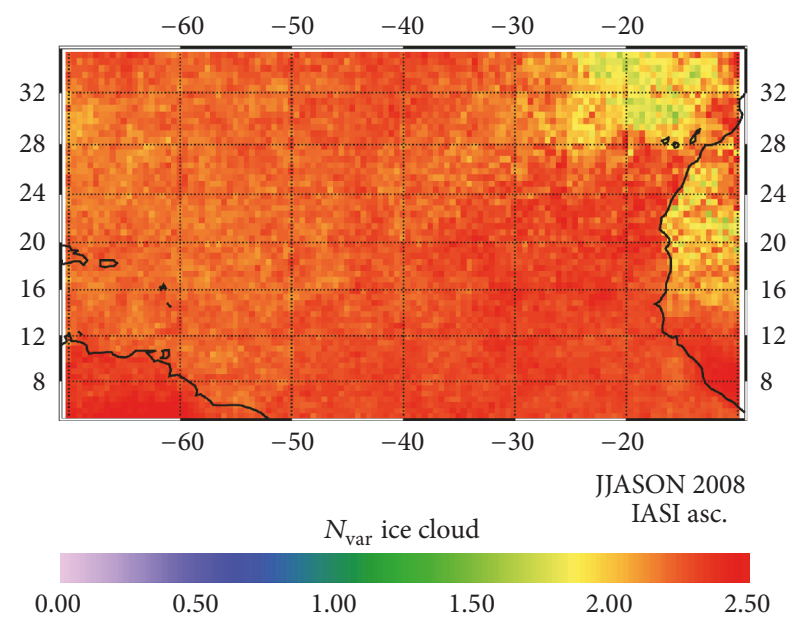

(d)

FIgURE 2: Average Shannon retrieval information content $I_{\text {ret }}(\mathrm{a}, \mathrm{c})$ and number of ice cloud independent variables $N_{\text {var }}(\mathrm{b}, \mathrm{d})$ as obtained from the IMARS retrieval for IASI descending $(a, b)$ and ascending $(c, d)$ overpasses for the hurricane season 2008 over the tropical North Atlantic Ocean.

retrieved independently, is significantly reduced. $N_{\text {var }}$ (cloud) includes only cloud information from individual pixels. This means that cloud fractional cover (CFC), which can be estimated from a set of pixels (see Section 3.2), is not included. If CFC is evaluated, that accounts for another independent variable. As cloud top temperature is not determined from the spectral signal, the 2.5 independent variables refer to ice cloud optical depth, effective radius, and ice water path. From theoretical considerations it is clear that these three are not completely independent and that $N_{\text {var }}$ (cloud) thus is expected to be smaller than 3 .

2.2. TRMM 3B42 Precipitation Estimates. Precipitation information in this study is taken from the TRMM (Tropical Rainfall Measuring Mission) 3B42 dataset [30] version 6. This product combines passive microwave and infrared satellite observations with rain gauge data in order to estimate 3hourly rain rate at a spatial resolution of $0.25^{\circ}$. Only rainfall observations collocated temporarily and spatially with
IMARS ice cloud observations are used for the analysis. Consequently, precipitation estimates without corresponding IMARS cloud observations are neglected. Spatial integration is performed by collocation of the $6 \mathrm{~km}$ (at nadir) IASI fieldof-view (FOV) with the respective TRMM $0.25^{\circ}$ grid boxes and averaging over the spatial fraction of TRMM grid boxes within the IASI FOV. Temporal integration corresponds to selection of the 3-hour window enveloping the IASI observation time for each FOV.

2.3. Dust Correlation Lengths. The statistical analysis of aerosol-cloud relationships requires assumptions about the coincidence of aerosol concentrations and cloud properties (see also Section 3.1). For satellite observations this is a problem, as it is (at least with currently used methods) impossible to simultaneously assess the aerosol load and cloud properties of a single observation (satellite pixel). Consequently it is necessary to use some type of spatial information for data aggregation. Spatial correlation lengths 
[31] are a useful means to assess the representativity of aerosol (or cloud) observations. Spatial correlation lengths for desert dust $\mathrm{AOD}\left(\mathrm{AOD}_{\text {dust }}\right)$ are calculated as the sum over the spatial autocorrelation function of $\mathrm{AOD}_{\text {dust }}$ [31]:

$$
\widehat{\mathrm{CL}}_{\mathrm{spat}}=\sum_{d=1}^{d_{\max }} \frac{\sum_{\delta=0}^{d_{\max }-d-1}\left(\mathrm{AOD}_{\mathrm{dust}}(\delta)-\langle\mathrm{AOD}\rangle\right)\left(\mathrm{AOD}_{\mathrm{dust}}(d+\delta)-\langle\mathrm{AOD}\rangle\right)}{\sum_{\delta=0}^{d_{\max }-1}\left(\mathrm{AOD}_{\text {dust }}(\delta)-\langle\mathrm{AOD}\rangle\right)^{2}} .
$$

The sum is evaluated with all observations within the maximum distance $d_{\max }$ of each FOV and the correlation at distance $d$ (inner fraction in (3)) is calculated for distances $\delta$ of the vector containing all available observations with $d<$ $d_{\max } \cdot\langle\cdot\rangle$ denotes the average of the observations taken into account. Equivalently to Schepanski et al. [31] the maximum distance for the correlation length has been set to $d_{\max }=$ $280 \mathrm{~km}$.

Figure 3 depicts the correlation lengths of desert dust over the tropical North Atlantic Ocean for the hurricane season 2008. Besides spatial correlation lengths also temporal correlation lengths (see [31]) are presented. It is entirely clear that the typical Atlantic Ocean dust plume is well expressed in the temporal correlation lengths, representing the correlated westward transport, and to a lesser degree, in the spatial correlation lengths, as the transport patterns and cloud interactions shift over the season. As Schepanski et al. [31] have clearly shown, correlation lengths are subject to temporal variation as well (for example resulting from shifting transport patterns in the case of desert dust). Consequently it is important to generate the correlation lengths for the same domain and period as the intended analysis.

\section{Theory: Bayesian Analysis of the Statistical Relationships between Aerosol Loading and Cloud Properties}

3.1. Assumptions. Cloud top properties are widely controlled by the convective structure within the cloud and especially by the altitude and temperature of cloud top and cloud base (e.g., [13, 32]). Thus any analysis of contrasting aerosolinfluenced clouds with clouds in pristine conditions is subject to influences of the convective structure and meteorological environment of the cloud field as well.

Many studies used cloud top temperature (CTT) to estimate vertical profiles of effective radius or other cloud properties inside the cloud (e.g., [3, 4, 33-35]). One example method has been demonstrated by Ramanathan et al. [4], Rudich et al. [33], or Christensen et al. [35] by using diagrams of effective radius as a function of cloud top temperature to identify the aerosol influence on droplet size. In their studies, the difference of aerosol-influenced profiles from background profiles represented the aerosol effect. Such an approach can also be used in a statistical sense for larger data volumes to characterize cloud properties and their relationship to dust load. Taking into account a cloud variable assumed to represent the meteorological state, several assumptions regarding the cloud development have to be made for such statistical analysis:
(1) Any aerosol influence on cloud properties is assumed to be instantaneous; that is, simultaneous observations of aerosols and clouds fully characterize the problem.

(2) Any cloud observable (for example optical depth) is a function of the meteorological state and the aerosol loading (as for example characterized by $\mathrm{AOD}_{\text {dust }}$ ) only. That means that no other variable than meteorological state (however defined) and aerosol loading affects the observed cloud property distribution.

(3) Histograms of cloud observations can be interpreted as probability distributions.

(4) The physical relationship between any cloud property and the variable characterizing the meteorological state depends on this state only and consequently the conditional probability is unique.

(5) Cloud top temperature (CTT) is a valid estimator for the meteorological state.

Assumption (1) is generally unproblematic in convective regimes, since their typical development time scales are much shorter than the aerosol residence time in the atmosphere. This is particularly true for transported Saharan dust compared to the typical development times of convective clouds (see temporal correlation lengths of Saharan dust in Figure 3). Assumption (2) needs more thought. It is fulfilled, when assumption (5) is valid, that is, when the full characterization of the meteorological state by the selected variable is sufficient. Assumption (3) seems to be unproblematic at first sight, but it requires some thorough consideration as well. For it to be valid, the probability distribution of cloud properties has to be stationary with space and time. This means that the cloud fields have to be statistically homogeneous. In essence, to fulfil this assumption the analysis region has to be selected in a way so that this homogeneity may safely be assumed. Assumption (4) is necessary in order to be able to adequately characterize the physical relationship between cloud property and meteorological state by joint histograms. Assumption (5) is the weakest one. For example, cirrus clouds and deep convective systems might have the same CTT, reflecting quite different meteorological states. Moreover, cloud top temperature also depends in a highly nonlinear way on microphysics and the environmental buoyancy. Also, stronger low-level moisture convergence may lead to intense convection, directly impacting on cloud top temperatures. Furthermore, the intensity of trade winds affects the amount of mineral dust transported from the Sahara to the Atlantic Ocean, as well as the lowlevel moisture convergence regardless of dust concentration. Consequently, the cloud top temperature alone is a strong 


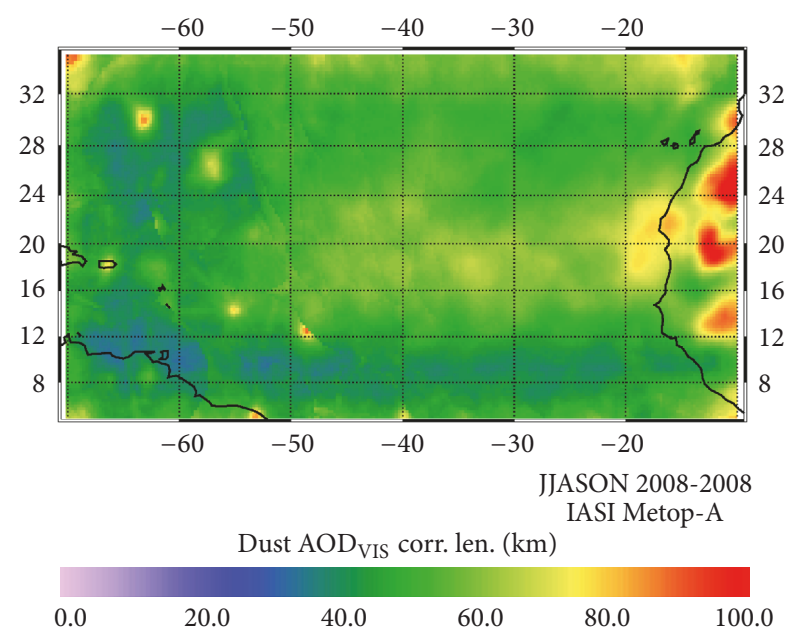

(a)

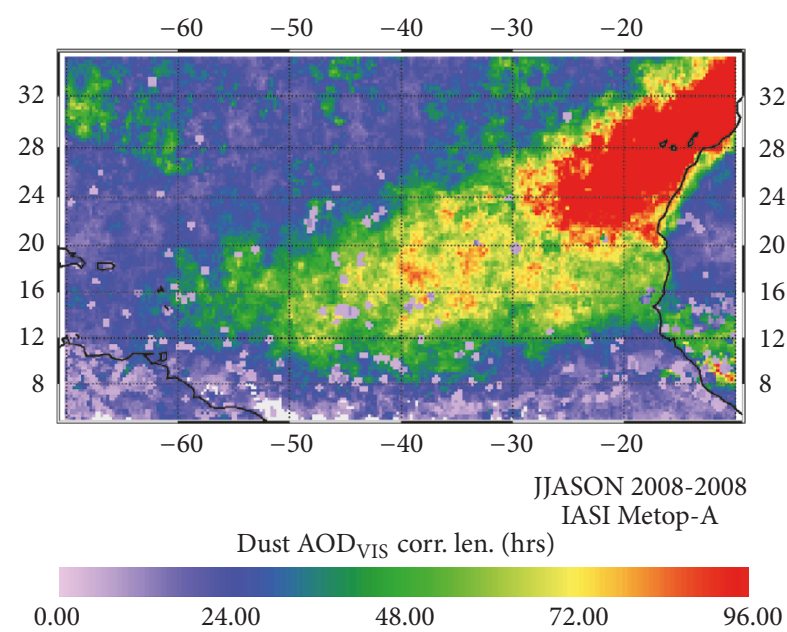

(b)

FIGURE 3: Spatial (a) and temporal (b) correlation lengths for desert dust retrieved from IASI with the IMARS method over the tropical North Atlantic Ocean. IASI observations of the entire hurricane season (JJASON) 2008 are used for the assessment.

simplification of the description of the meteorological state. To overcome these weaknesses, it can be assumed that with sufficiently large sample size the statistical significance of the average state increases and the analysis results become valid. The main justification is that for the analysis of remotely sensed data not many more possibilities are available without violating the requirement of consistent observational data. The interpretation of the statistical results therefore requires a thorough reflection on this assumption. In addition, by selecting a dataset for a limited period and region with rather homogeneous conditions we apply another means to reduce the impact of variable meteorological conditions.

As an additional complication it is not straightforward to assume that satellite observations of aerosol in the vicinity of clouds really represent the amount of aerosol entrained into the cloud system where they act as modulation agent for cloud properties. In order to generate a set of coincidences for dust loading and cloud properties, the spatial correlation lengths for IMARS AOD $\mathrm{Dust}_{\text {are }}$ used to generate a continuous AOD field for each observation time step. In this sense, for each IASI field-of-view, all available $\mathrm{AOD}_{\text {dust }}$ retrievals within the corresponding correlation length are averaged and used as effective $\mathrm{AOD}_{\text {dust }}$ for the analysis. This approach allows having valid $\mathrm{AOD}_{\text {dust }}$ values from satellite observations also at the location of the cloud properties observations.

After having generated the continuous $\mathrm{AOD}_{\text {dust }}$ fields, IMARS cloud observations are subdivided into three different subsets of dust loading. These represent pristine background conditions, moderate dust loading, and high dust loading. Pristine conditions are represented by all cloud observation with coincident $\mathrm{AOD}_{\text {dust }}<0.15$. Moderate dust loading is defined by $0.15 \leq \mathrm{AOD}_{\text {dust }} \leq 0.6$, while high dust loading samples all cloud observations connected to $\mathrm{AOD}_{\text {dust }}>$ 0.6. These thresholds have heuristically been based on the accuracy of the IMARS retrieval (see the appendix) for the lower bound and on a trade-off between accuracy and available data numbers for sufficiently large sample sizes for the higher threshold.

3.2. Histogram Generation. As a starting point, CTT histograms are determined from all IMARS ice cloud observations in the analysis region for the three different dust loading sets "background" (" $b$ ", black colour in plots), "moderate" (" $m$ ", blue), and "high" (" $h$ ", red). As outlined above, the cloud top temperature is used to reflect the meteorological state, that is, the development of the clouds. Other variables such as ice water path (IWP) can be used as alternative constraining variable (i.e., representing the meteorological state) as will be shown in comparing Tables 1 and 2. Histograms are made up of 50 bins, for CTT between $195 \mathrm{~K}$ and $275 \mathrm{~K}$. Consequently the CTT bin size is $1.6 \mathrm{~K}$. Major statistical quantities of the CTT distributions for the three dust loading subsets are provided alongside with the histograms (see Figure 4): the mean value ("mean"), the standard deviation ("SDev"), the skewness ("skew"), and the median (" $Q_{50}$," representing the 50 th percentile).

Moreover the distribution Shannon Information Content $I$ (" $I(H)$ " in the figure annotations, corresponding to $I(X)$ in (4)) is used as a distribution descriptor. It is calculated from the histogram densities $H$ as follows $[27,28,36]$ :

$$
I(X)=-\sum_{x \in X} H(x) \cdot \log _{2}(H(x)) .
$$

The Shannon Information Content describes the complexity of a probability distribution. Accordingly, changes in $I$ signify the presence of processes which impact the overall complexity of the cloud variable distribution (see [28] for a discussion on the different interpretations of $I$ ). The IMARS retrieval information content (see (1)) is a special case of such a distribution information content where the set $X$ in (4) consists of two elements only. In the cloud variable histograms used for the statistical analysis of dust-cloud 
TABLE 1: Deviation statistics for four cloud variables COD, $R_{\text {eff }}$, IWP, and CFC and for RR for moderate and high dust loading subsets. Here, CTT has been used to describe the meteorological state.

\begin{tabular}{lccccc}
\hline & $\langle\Delta H(\mathrm{COD})\rangle$ & $\begin{array}{c}\left\langle\Delta H\left(R_{\mathrm{eff}}\right)\right\rangle \\
{[\mu \mathrm{m}]}\end{array}$ & $\begin{array}{c}\langle\Delta H(\mathrm{IWP})\rangle \\
{\left[\mathrm{g} / \mathrm{m}^{2}\right]}\end{array}$ & $\begin{array}{c}\langle\Delta H(\mathrm{CFC})\rangle \\
\langle\Delta H(\mathrm{RR})\rangle \\
{[\mathrm{mm} / \mathrm{h}]}\end{array}$ \\
\hline $\begin{array}{llll}\text { Moderate dust load } n=455686, n_{\mathrm{RR}>0}=9687 \\
\Delta \mu\end{array}$ & $+0.51 \pm 0.03$ & $-1.13 \pm 0.08$ & $+16.6 \pm 0.8$ & $-0.08 \pm 0.01$ & $-0.32 \pm 0.06$ \\
$\Delta \sigma$ & $+0.46 \pm 0.01$ & $+1.27 \pm 0.06$ & $+15.7 \pm 0.5$ & $+0.05 \pm 0.01$ & $-0.21 \pm 0.04$ \\
$\Delta|\gamma|$ & $-0.69 \pm 0.03$ & $-0.24 \pm 0.03$ & $-0.87 \pm 0.03$ & $-0.40 \pm 0.03$ & $+1.20 \pm 0.18$ \\
$\Delta Q_{50}$ & $+0.31 \pm 0.03$ & $-2.04 \pm 0.10$ & $+10.2 \pm 0.9$ & $-0.08 \pm 0.01$ & $-0.20 \pm 0.07$ \\
$\Delta I$ & $+0.48 \pm 0.08$ & $+0.34 \pm 0.08$ & $+0.49 \pm 0.08$ & $+0.21 \pm 0.08$ & $-1.12 \pm 0.75$ \\
\hline High dust load $n=46992, n_{\mathrm{RR}>0}=678$ & & & & & \\
$\Delta \mu$ & $+1.46 \pm 0.09$ & $-1.71 \pm 0.24$ & $+47.7 \pm 3.3$ & $+0.12 \pm 0.01$ & $-0.07 \pm 0.11$ \\
$\Delta \sigma$ & $+1.05 \pm 0.08$ & $+0.63 \pm 0.17$ & $+32.6 \pm 2.2$ & $-0.01 \pm 0.01$ & $-0.49 \pm 0.08$ \\
$\Delta|\gamma|$ & $-1.17 \pm 0.08$ & $-0.50 \pm 0.08$ & $-1.33 \pm 0.08$ & $+1.55 \pm 0.08$ & $-1.44 \pm 0.67$ \\
$\Delta Q_{50}$ & $+1.22 \pm 0.12$ & $-4.08 \pm 0.31$ & $+40.8 \pm 4.0$ & $+0.12 \pm 0.01$ & $+0.31 \pm 0.14$ \\
$\Delta I$ & $+0.89 \pm 0.44$ & $+0.19 \pm 0.44$ & $+0.92 \pm 0.44$ & $-1.91 \pm 0.44$ & $-0.38 \pm 1.15$ \\
\hline
\end{tabular}

TABLE 2: Deviation statistics for four cloud variables COD, $R_{\mathrm{eff}}, \mathrm{CTT}$, and CFC and for RR for moderate and high dust loading subsets. Here, IWP has been used to describe the meteorological state.

\begin{tabular}{lccccc}
\hline & $\langle\Delta H(\mathrm{COD})\rangle$ & $\begin{array}{c}\left\langle\Delta H\left(R_{\mathrm{eff}}\right)\right\rangle \\
{[\mu \mathrm{m}]}\end{array}$ & $\begin{array}{c}\langle\Delta H(\mathrm{CTT})\rangle \\
{[\mathrm{K}]}\end{array}$ & $\begin{array}{c}\langle\Delta H(\mathrm{CFC})\rangle \\
{[\Delta H(\mathrm{RR})\rangle} \\
{[\mathrm{mm} / \mathrm{h}]}\end{array}$ \\
\hline $\begin{array}{l}\text { Moderate dust load } n=455686, n_{\mathrm{RR}>0}=9687 \\
\Delta \mu\end{array}$ & $+0.00 \pm 0.03$ & $-2.69 \pm 0.08$ & $-4.5 \pm 0.1$ & $-0.25 \pm 0.01$ & $-0.80 \pm 0.06$ \\
$\Delta \sigma$ & $-0.03 \pm 0.01$ & $+2.58 \pm 0.06$ & $-0.1 \pm 0.1$ & $-0.16 \pm 0.01$ & $-0.03 \pm 0.04$ \\
$\Delta|\gamma|$ & $+0.04 \pm 0.03$ & $-0.91 \pm 0.03$ & $-0.61 \pm 0.03$ & $+2.04 \pm 0.03$ & $+0.06 \pm 0.18$ \\
$\Delta Q_{50}$ & $+0.00 \pm 0.03$ & $-2.04 \pm 0.09$ & $-8.6 \pm 0.2$ & $-0.24 \pm 0.01$ & $-0.10 \pm 0.08$ \\
$\Delta I$ & $-0.02 \pm 0.08$ & $+0.66 \pm 0.08$ & $+0.28 \pm 0.08$ & $-1.94 \pm 0.08$ & $-0.55 \pm 0.75$ \\
\hline High dust load $n=46992, n_{\mathrm{RR}>0}=678$ & & & & & \\
$\Delta \mu$ & $+0.00 \pm 0.09$ & $-2.09 \pm 0.26$ & $+7.5 \pm 0.5$ & $-0.16 \pm 0.01$ & $-0.03 \pm 0.14$ \\
$\Delta \sigma$ & $-0.01 \pm 0.08$ & $+2.31 \pm 0.18$ & $-0.7 \pm 0.5$ & $-0.05 \pm 0.01$ & $-0.32 \pm 0.10$ \\
$\Delta|\gamma|$ & $+0.01 \pm 0.08$ & $-0.63 \pm 0.08$ & $-0.59 \pm 0.08$ & $+1.27 \pm 0.08$ & $-1.18 \pm 0.67$ \\
$\Delta Q_{50}$ & $+0.00 \pm 0.12$ & $-1.02 \pm 0.33$ & $-11.4 \pm 0.6$ & $-0.20 \pm 0.01$ & $+0.31 \pm 0.18$ \\
$\Delta I$ & $-0.02 \pm 0.44$ & $+0.65 \pm 0.44$ & $+0.18 \pm 0.44$ & $-1.00 \pm 0.44$ & $-0.16 \pm 1.15$ \\
\hline
\end{tabular}

relationships the set $X$ consists of 50 elements, that is, the 50 histogram bins.

Similar histograms for all three dust loading subsets (and corresponding statistical values) are generated for all other available cloud variables. In the case of IMARS ice cloud observations over the tropical North Atlantic Ocean these are cloud optical depth (COD), cloud effective radius $\left(R_{\mathrm{eff}}\right)$, Ice Water Path (IWP), and cloud fractional cover (CFC, evaluated as the fraction of cloud detection instances within the dust correlation length). Additionally, the corresponding rain rate $(\mathrm{RR})$ from the TRMM dataset is determined.
Furthermore, joint histograms of these cloud variables and the constraining variable, that is, CTT, are generated for the three dust loading classes as well.

These joint histograms represent the common observation densities of a pair of cloud top temperature and the respective cloud properties. The joint histograms also consist of 50 bins along each dimension, that is, of 2500 probability entries.

All histograms are normalized; thus the sum over all bins equals 1 for each histogram. With this normalization the histograms can be interpreted as a discrete representation 


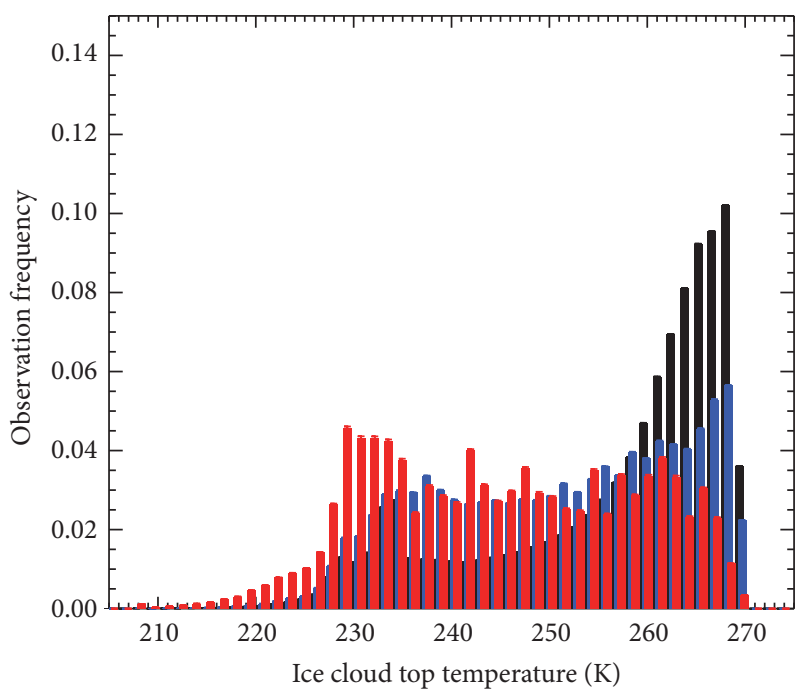

$\begin{array}{lll}\text { Mean: } 257.41 & \text { Mean: } 251.72 & \text { Mean: } 245.58 \\ \text { SDev: } 12.40 & \text { SDev: } 12.91 & \text { SDev: } 13.46 \\ \text { Skew: }-1.06 & \text { Skew: }-0.31 & \text { Skew: }-0.02 \\ Q_{50}: 262.14 & Q_{50}: 252.14 & Q_{50}: 245.00 \\ I(H): 4.58 & I(H): 4.98 & I(H): 5.11\end{array}$

(a)

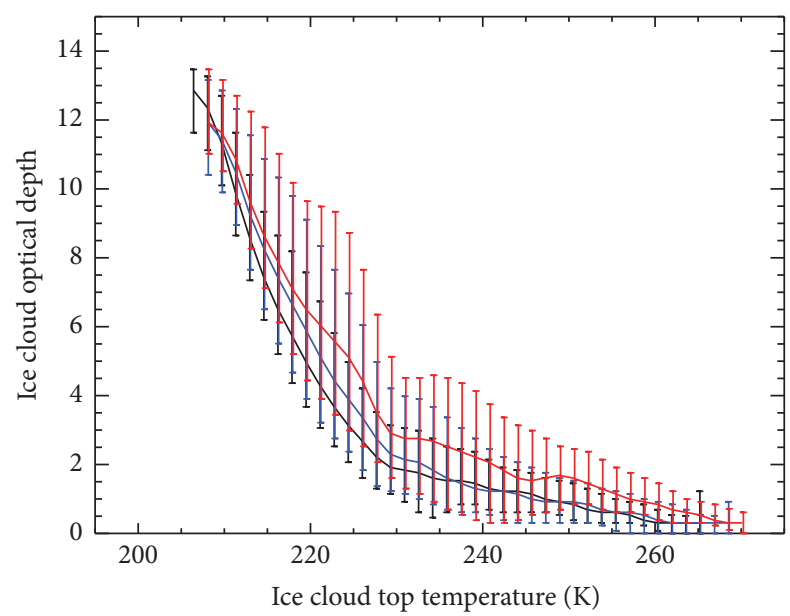

(b)

FIgURE 4: Ice cloud top temperature histograms H(CTT) (a) and joint PDFs between CTT and ice cloud optical depth, H(CTT I COD) (b), for all three dust loading subsets (in three colours for the three dust loading classes). The CTT histograms for the three dust loading classes are accompanied by the set of statistical descriptors. The joint PDFs are depicted as median value (solid line) and 25th and 75th percentile (bars) for each CTT bin. Black represents pristine background conditions, blue moderate dust loading, and red the high dust loading class.

of the probability density function (PDF) without any need to determine an analytical form of the PDFs. For sufficiently large sample sizes, histogram bins, reproducing relative observation frequency, are good representations of the probability of an observation within that bin. Consequently, the histogram frequency represents the integral of the PDF over the bin width (and thus probability and not probability density).

3.3. Bayesian Estimation of Pristine Background Distributions. The classical notation of Bayes' theorem describes the calculation of conditional probabilities [37, 38]:

$$
P(x \mid y)=\frac{P(y \mid x) \cdot P(x)}{P(y)} .
$$

For the analysis of relationships between aerosols and clouds, the probabilities can be expressed as histograms [36], so the relationship can be reformulated to

$$
H(x \mid y)=\frac{H(y \mid x) \cdot H(x)}{H(y)},
$$

where $H$ describes the histogram frequency. So far, the meaning of $x$ and $y$ has not yet been specified. Considering the assumptions for the analysis as outlined in Section 3.1, one can identify $x$ with any cloud observable (such as for example COD) and $y$ with the corresponding meteorological state. Thus with (5) the conditional probability of cloud observable value $x$ under meteorological state $y$ is calculated from the joint probability of $y$ and $x$, the prior (unconditional) probability of the cloud observable value $x$, and the prior (unconditional) probability of the meteorological state $y$. In this interpretation, assumption (4) allows exchanging the conditional probability with the joint probability.

Using CTT as an estimator for the meteorological state according to assumption (5), this yields the full formulation of the probability estimate $\widehat{H}$ for cloud observable value $x$ under meteorological state $y_{\{m, h\}}$ starting from meteorological state

$$
H\left(y_{\{m, h\}}\right)=\sum_{k} H\left(y_{\{m, h\}} \mid x_{\{m, h\}}[k]\right)
$$

background conditions $H\left(x_{b}\right)$ and the meteorology-cloud parameter relationship $H\left(\mathrm{CTT}_{\{m, h\}} \mid x\right)$ :

$$
\begin{aligned}
\widehat{H} & \left(x \mid \mathrm{CTT}_{\{m, h\}}\right) \\
& =\sum_{i}\left[\frac{H\left(\mathrm{CTT}_{\{m, h\}}[i] \mid x_{\{m, h\}}\right) \cdot H\left(x_{b}\right)}{\sum_{k} H\left(\mathrm{CTT}_{\{m, h\}}[i] \mid x_{\{m, h\}}[k]\right)}\right] .
\end{aligned}
$$

In (7) and (8), the subscripts to variables indicate the background $(b)$ moderate $(m)$ and high $(h)$ dust loading subsets. The histogram estimator $\widehat{H}$ is calculated independently for the moderate and high dust loading subsets (as indicated by the subscripts $\{m, h\})$.

This Bayesian histogram estimator (also referred to as projection in the analysis) represents the distribution to test against the distribution of cloud observable values under pristine background conditions, reflecting the corresponding meteorological state, and the covariability of meteorological state and cloud variable in the corresponding dust loading subset. Consequently $\widehat{H}(x \mid \mathrm{CTT})$ statistically accounts and corrects for differences in the convective structure for 


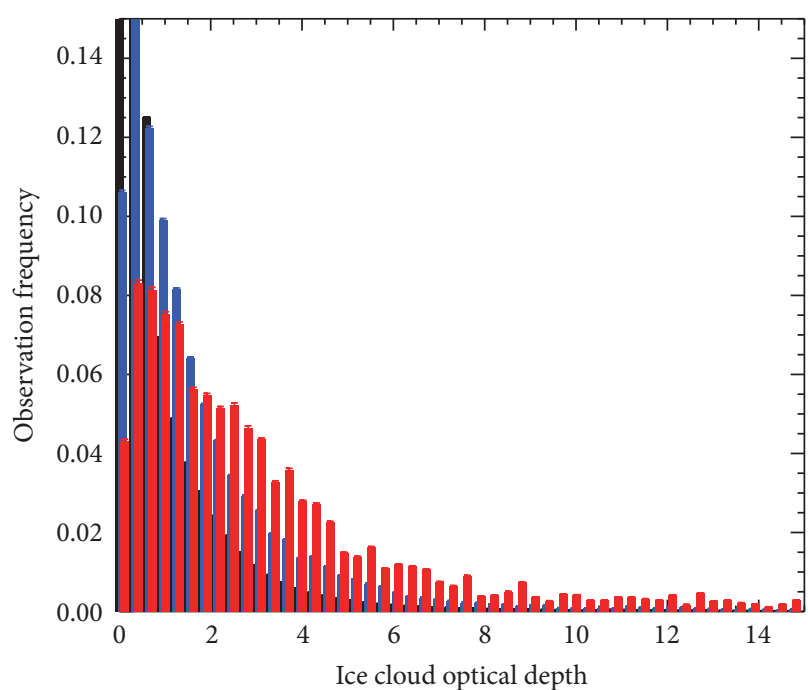

$\begin{array}{lll}\text { Mean: } 0.92 & \text { Mean: } 1.72 & \text { Mean: } 3.06 \\ \text { SDev: } 1.49 & \text { SDev: } 2.10 & \text { SDev: } 2.99 \\ \text { Skew: } 3.96 & \text { Skew: } 2.61 & \text { Skew: } 1.71 \\ Q_{50}: 0.31 & Q_{50}: 0.92 & Q_{50}: 2.14 \\ I(H): 3.10 & I(H): 4.01 & I(H): 4.77\end{array}$

(a)

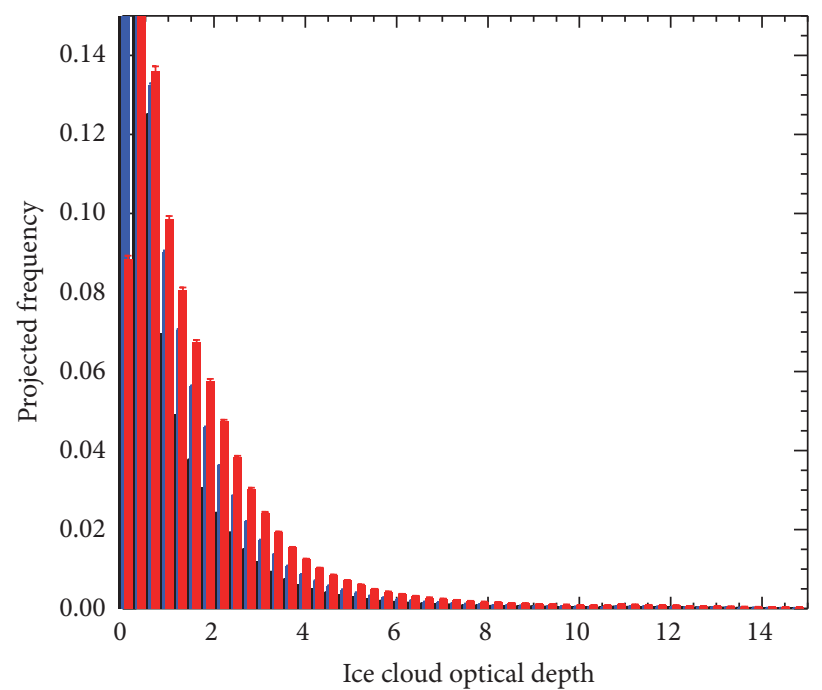

$\begin{array}{lll}\text { Mean: } 0.92 & \text { Mean: } 1.21 & \text { Mean: } 1.60 \\ \text { SDev: } 1.49 & \text { SDev: } 1.64 & \text { SDev: } 1.94 \\ \text { Skew: } 3.96 & \text { Skew: } 3.30 & \text { Skew: } 2.88 \\ Q_{50}: 0.31 & Q_{50}: 0.61 & Q_{50}: 0.92 \\ I(H): 3.10 & I(H): 3.53 & I(H): 3.89\end{array}$

(b)

FIGURE 5: Observed ice cloud optical depth histogram $H(\mathrm{COD})$ (a) and meteorological-state-normalized Bayesian estimator $\widehat{H}(\mathrm{COD})$ (b) for all three dust loading subsets together with accompanying distribution statistics. Black again represents pristine background conditions, blue moderate dust loading, and red the high dust loading class.

the different cloud samples. Figure 5 shows the observed histogram $H$ for ice cloud optical depth alongside with the projected histogram $\widehat{H}$ (generated with the Bayesian estimate (8)), which is considered to reflect the impacts of the meteorological state for the different aerosol subsets.

\subsection{Comparison of Estimated and Observed Distributions.} The deviation of the observed histogram $H$ of variable $x$ for the moderate and high dust loading subset from the Bayesian estimator $\widehat{H}$ (projection) of the pristine background under the corresponding meteorological state can be interpreted as quantitative indicator for the relationship between airborne dust and cloud property $X$. This observation density difference is simply calculated as

$$
\Delta H\left(x_{\{m, h\}}\right)=H\left(x_{\{m, h\}}\right)-\widehat{H}\left(x \mid \mathrm{CTT}_{\{m, h\}}\right) .
$$

The resulting $\Delta H$ provides the probability difference between observation and estimator for each bin and thus has the same dimension as the histograms. Especially for non-Gaussian PDFs it can be very helpful to analyse the distribution changes and not only the change in average values.

Besides the deviation for each histogram bin also the average difference of observed cloud variable $x$ from the projected background over the full histogram ( $N$ bins) is presented for both dust load classes as

$$
\left\langle\Delta H\left(x_{\{m, h\}}\right)\right\rangle=\sum_{i=1}^{N} \Delta H\left(x_{\{m, h\}}[i]\right) \cdot x_{\{m, h\}}[i] .
$$

Figure 6 shows an example analysis of the difference $\Delta H(\mathrm{COD})$ for the two classes "moderate" and "high" aerosol loading. Average statistical quantity deviations are calculated with (10). A shift in ice cloud optical depth to larger values can be observed for both classes, where the shift increases from moderate to high dust loading.

\section{Results}

Figure 7 presents the distribution of ice cloud variables COD, $R_{\text {eff }}$, CFC, and CTT in dependence of $\mathrm{AOD}_{\text {dust }}$, evaluated in 50 bins for values between 0 and 1 . The cloud variables depicted in Figure 7 have not been corrected or stratified but simply represent the full sample of ice cloud observations throughout the hurricane season 2008. The cloud variable distributions for each $\mathrm{AOD}_{\text {dust }}$ bin are represented by the mean value (blue solid line), the median (red solid line), the 25th and 75th percentiles (red dashed lines), and the 10th and 90th percentiles (bars). The evolution of the distribution statistics with $\mathrm{AOD}_{\text {dust }}$ indicates (without accounting for differences in the meteorological states of the samples representing $\mathrm{AOD}_{\text {dust }}$ bins) an increase of COD and IWP with increasing $\mathrm{AOD}_{\text {dust }}$. $R_{\text {eff }}$ does not seem to be equally affected although a decrease in terms of mean and median is evident for high dust loadings. CFC shows a significant increase with $\mathrm{AOD}_{\text {dust }}$, which of course impacts on the sample sizes for high dust loads, as can be seen in the increased noise of distribution parameters between bins for $\mathrm{AOD}_{\text {dust }}>0.6$. 


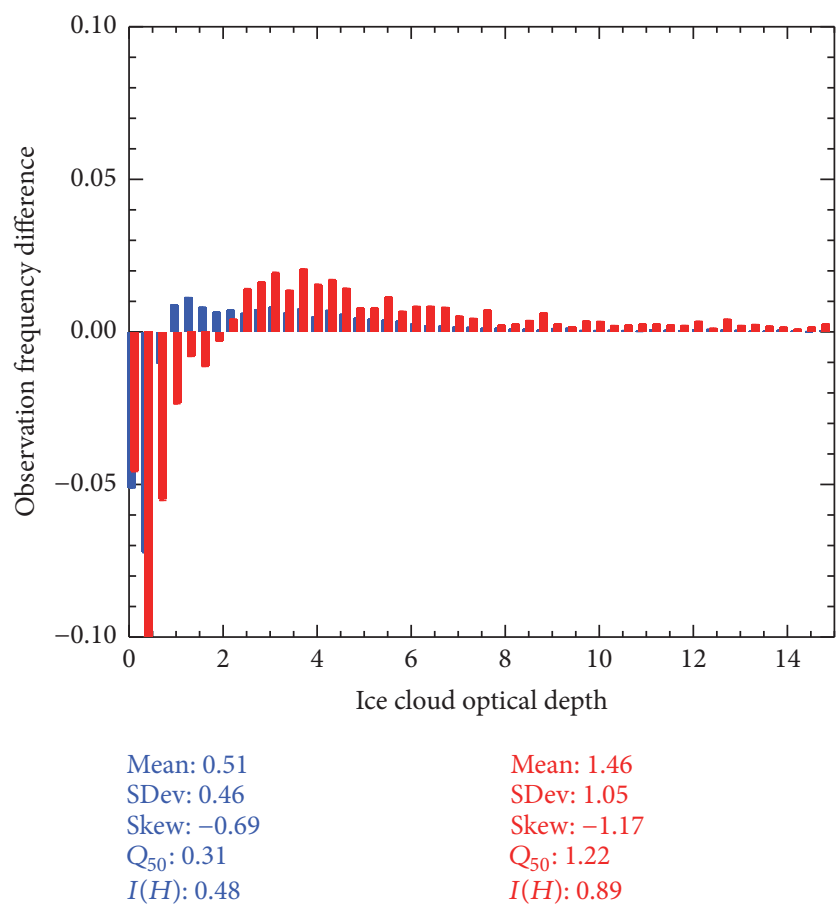

Figure 6: Difference $\Delta H(C O D)$ between observed ice cloud optical depth histogram $H(\mathrm{COD})$ for the moderate (blue) and high (red) dust loading subsets and Bayesian estimator $\widehat{H}(\mathrm{COD})$ together with accompanying distribution statistics differences.

However, as the $\mathrm{AOD}_{\text {dust }}$ bins do not represent homogeneous meteorological conditions, no reliable conclusions can be drawn from these observations alone. Consequently the analysis formalism presented in Section 3 has been applied and evaluated for the IMARS observations over the domain and period as defined in Section 2. The analysis method results in histogram differences as presented in Figure 6. For simplicity the histogram differences are presented and evaluated in terms of deviations of the mean value $(\mu)$, standard deviation $(\sigma)$, and skewness $(\gamma)$ as well as median value $\left(Q_{50}\right)$ and distribution information content $(I)$. The deviation of skewness from the background distribution is presented as absolute value $(\Delta|\gamma|)$, ignoring the direction of the skewness. Thus a negative value represents a less skewed observed distribution compared to the estimate whereas a positive value signifies a more skewed observed distribution. Results for the analysis using CTT as constraining variable for the meteorological state (see (8)) are presented in Table 1.

Uncertainties for $\mu, \sigma, \gamma$, and $Q_{50}$ follow from the standard errors of the moments ([39]; Benedict and Gould, 1996; [40]) based on the standard deviations of the observed distributions. The uncertainty calculation for the information content follows Shannon [29]. The average noise level is calculated as the square root of the sum (from $N$ bins) of individual probability uncertainties in the histogram as determined from the overall number of observations $n$. This histogram based noise level is used as uncertainty constraint for the statistical moments and the median as well in order to account for the additional uncertainty brought about by the aggregation into bins of finite width (see discussion in [29]). Otherwise the uncertainties from potentially large numbers of observations would not reflect this additional aggregation uncertainty. The uncertainties are thus not only functions of the overall numbers of observations but of the ratio between the number of histogram bins and the number of observations.

It is assumed that the uncertainties of the moments (denoted here as $\widehat{s}$ in order to discriminate them from the standard deviation $\sigma$ of the observations) follow a Gaussian distribution, although the sampled variables themselves may have non-Gaussian distributions (see [29]; Benedict and Gould, 1996; [40]). They are calculated as

$$
\begin{aligned}
\widehat{s}(\mu(X)) & =\sqrt{\frac{N}{n}} \sigma(X), \\
\widehat{s}(\sigma(X)) & =\sqrt{\frac{N}{2(n-1)}} \sigma(X), \\
\widehat{s}(\gamma(X)) & =\sqrt{\frac{6 N}{n}}, \\
\widehat{s}\left(Q_{50}(X)\right) & =\sqrt{\frac{\pi N}{2 n}} \sigma(X), \\
\widehat{s}(I(X)) & =\ln \left(1+\sqrt{2 \pi e \sqrt{\frac{N}{n}}}\right) .
\end{aligned}
$$

The analysis results indicate a general increase of COD and correspondingly IWP, in dust affected ice clouds, with higher magnitudes of changes for high dust loads than for moderate dust loading. Ice cloud effective radius decreases in the dust affected subsets on average, but the spread of its distribution increases. The mean effect for cloud fractional cover is not as conclusive, as the mean value increases under moderate dust loads and decreases in the vicinity of high $\mathrm{AOD}_{\text {dust }}$. It is evident from Table 1 that not only is the average of cloud properties shifted for dust affected clouds, but the dust influence changes the whole shape of the distributions, as indicated by the shifts in standard deviation and skewness as well as asymmetric shifts for mean and median values.

For testing the robustness of the analysis and analysing the role of CTT as meteorology descriptor in the dust-ice cloud relationships, the same analysis has been performed with IWP as constraining variable (i.e., representing the cloud development and thus the meteorological state). Then $\Delta H(\mathrm{IWP})$ is no longer accessible, but $\Delta H(\mathrm{CTT})$ can be evaluated. Results are presented in Table 2. With this approach the histogram differences in COD vanish completely, whereas the magnitude of changes in $R_{\text {eff }}$ and CFC increases and the sign of those changes remains (except for CFC under high dust loading). Cloud top temperature is decreased under dust influence in this analysis only for moderate dust load but is increased for high dust load; the standard deviation of the CTT distributions remains rather unaffected and the magnitude of the skewness decreases (i.e., the distributions tend to become more symmetric). The median shift is stronger than the mean value shift for both dust classes. 


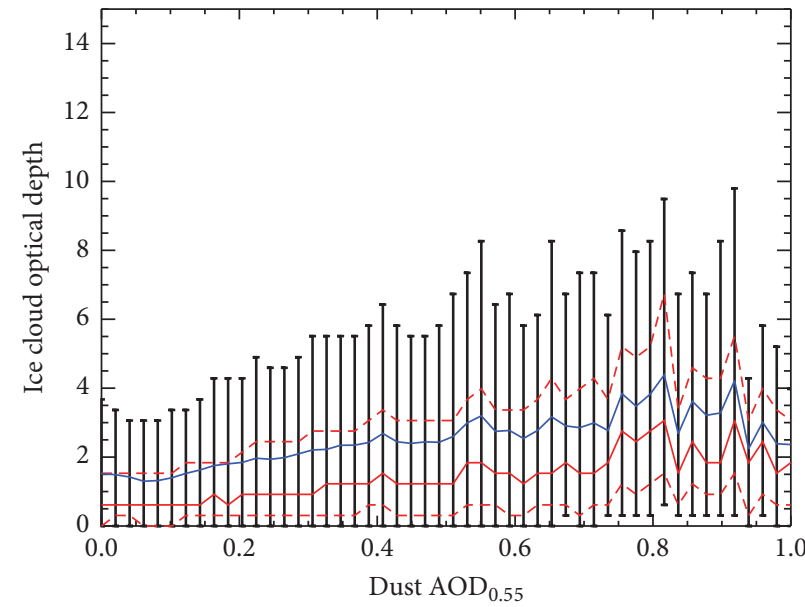

(a)

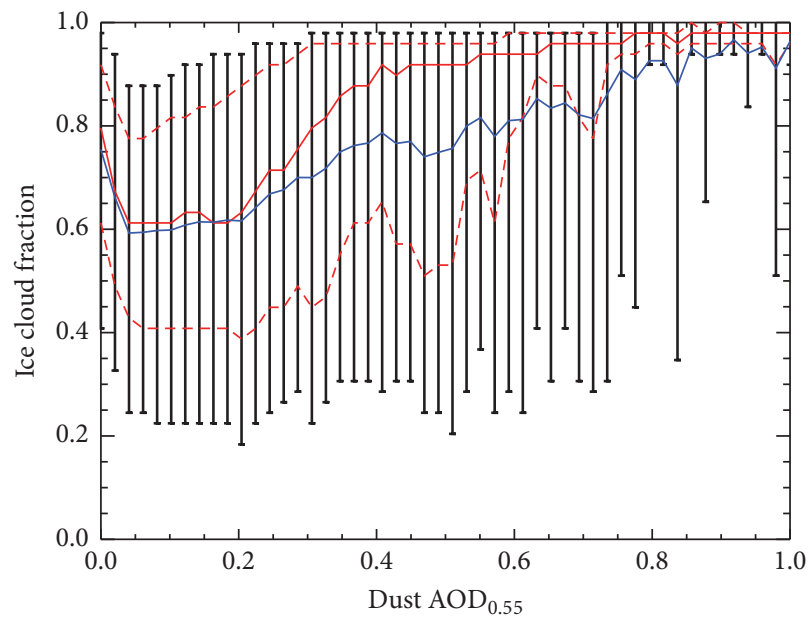

(c)

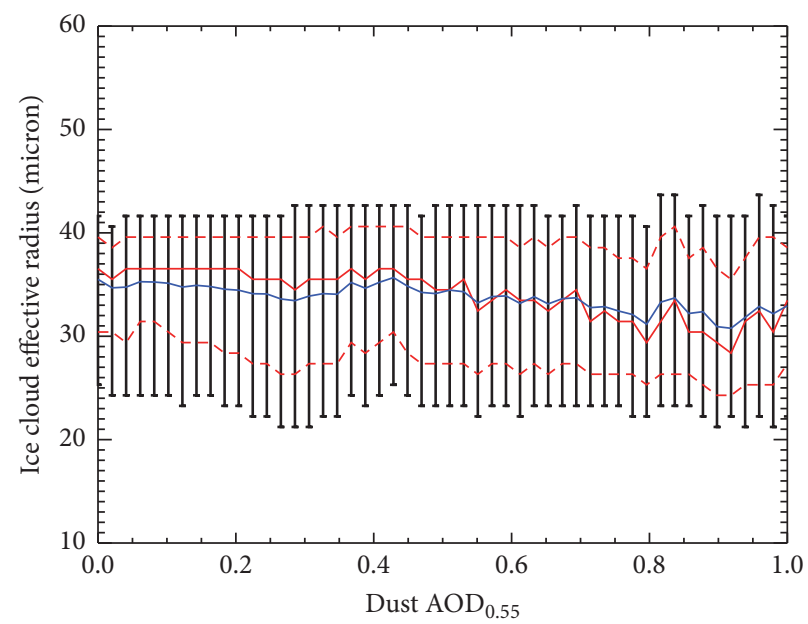

(b)

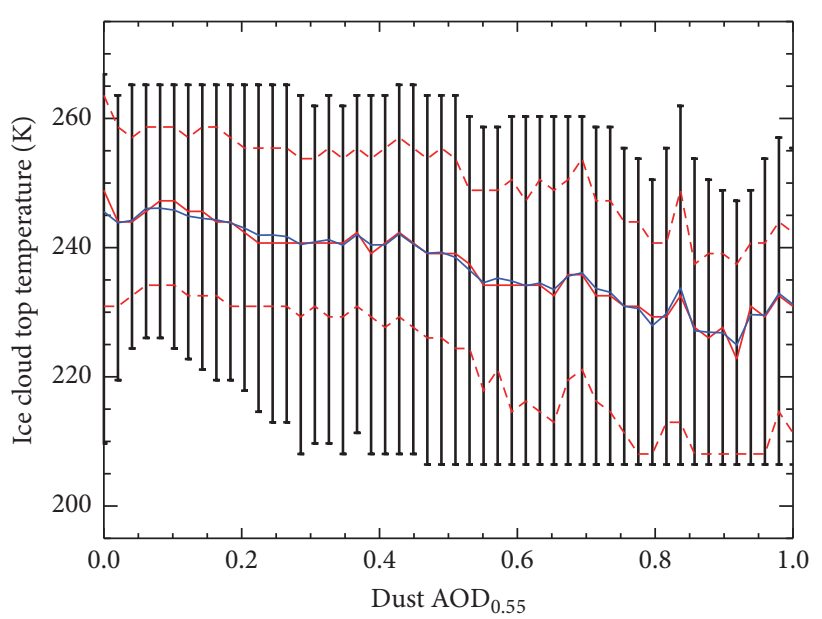

(d)

FIGURE 7: Representation of COD (a), $R_{\text {eff }}(\mathrm{b})$, CFC (c), and CTT (d) distribution for 50 bins of AOD dust between 0 and 1.0. In each plot, the red solid line represents the distribution median value, the blue line is the mean, the dashed red lines are deliminations for the 25th and 75th percentiles, and the bars represent the 10th and 90th percentiles.

Deep ice clouds (in the meaning of high-reaching and optically thick clouds; see, e.g., [25]) can be defined in the analysis by CTT $<240 \mathrm{~K}$ (i.e., pure ice tops with no liquid water content) and by baseline temperature $T_{\text {base }}<240 \mathrm{~K}$ as well. The baseline temperature is the maximum temperature observed within the IASI spectra [19]. The condition that $T_{\text {base }}$ is lower than the threshold for homogeneous freezing rejects semitransparent cloud layers, potentially above lower warm top clouds, from the sample. By this approach a sample is generated, which includes deep clouds but filters out thin cirrus layers. Although the combination of CTT and $T_{\text {base }}$ filters is of course COD dependent, the filtering is performed by only confining the permitted range of CTT, and thus of the constraining variable describing the meteorological state, without definite thresholds on COD or IWP. Figure 8 shows the observation histograms for ice water path and ice cloud effective radius as retrieved from IASI with the IMARS method for all ice cloud observations and for deep ice clouds only. It is clearly evident that the deep ice cloud subset features quite different statistics than the "all ice clouds" set. This can especially be seen in the bimodal structure of the effective radius. It also becomes evident from the histograms that the "high dust loading" class in combination with deep ice clouds only offers a limited sample size and that any conclusions drawn from that set have to be interpreted with great caution.

The analysis results for the "deep ice clouds only" subset are presented in Table 3. Especially in interpreting the results for the moderate dust load class it is evident that the relationship between Saharan dust and ice cloud properties differs from the one obtained for all ice clouds (shown in Table 1). In this case optical depth and ice water path are decreased in dust affected observations, whereas the effective radius is increased. For ice cloud fractional cover the shift of 


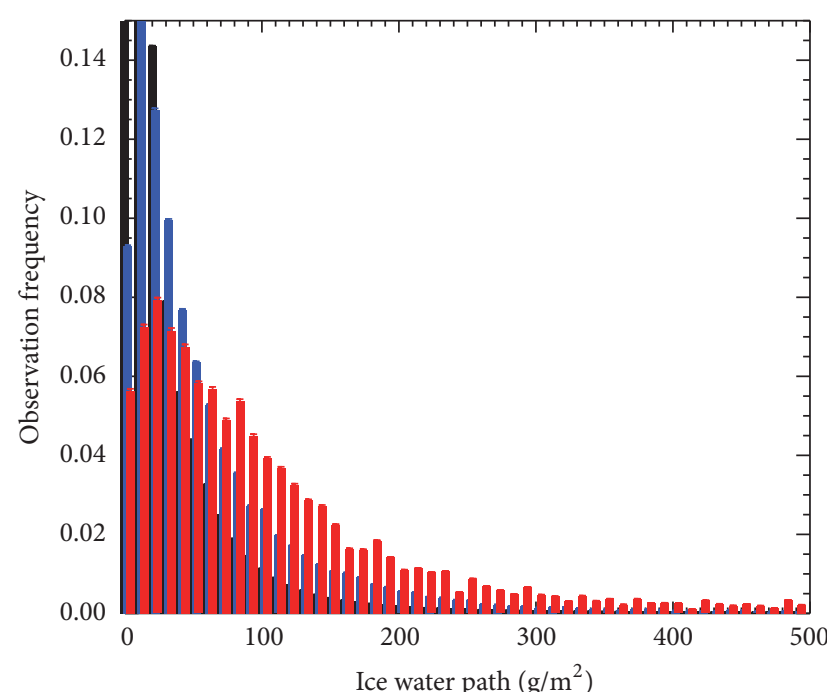

Mean: 32.86

SDev: 50.69

Skew: 4.04

$Q_{50}: 10.20$

$I(H): 3.14$

$\begin{array}{ll}\text { Mean: } 58.99 & \text { Mean: } 102.57 \\ \text { SDev: } 71.51 & \text { SDev: } 98.92 \\ \text { Skew: } 2.49 & \text { Skew: } 1.65 \\ Q_{50}: 30.61 & Q_{50}: 71.43 \\ I(H): 4.03 & I(H): 4.80\end{array}$

(a)

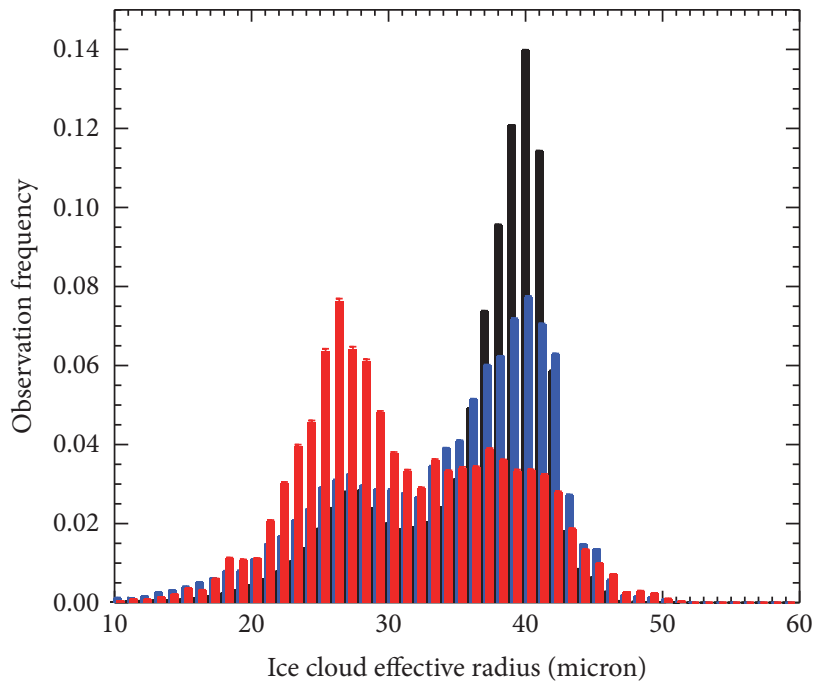

$\begin{array}{lll}\text { Mean: } 36.61 & \text { Mean: } 34.49 & \text { Mean: } 31.28 \\ \text { SDev: } 6.05 & \text { SDev: } 7.57 & \text { SDev: } 7.41 \\ \text { Skew: }-1.19 & \text { Skew: }-0.69 & \text { Skew: } 0.21 \\ Q_{50}: 38.57 & Q_{50}: 35.51 & Q_{50}: 29.39 \\ I(H): 4.21 & I(H): 4.76 & I(H): 4.81\end{array}$

(c)

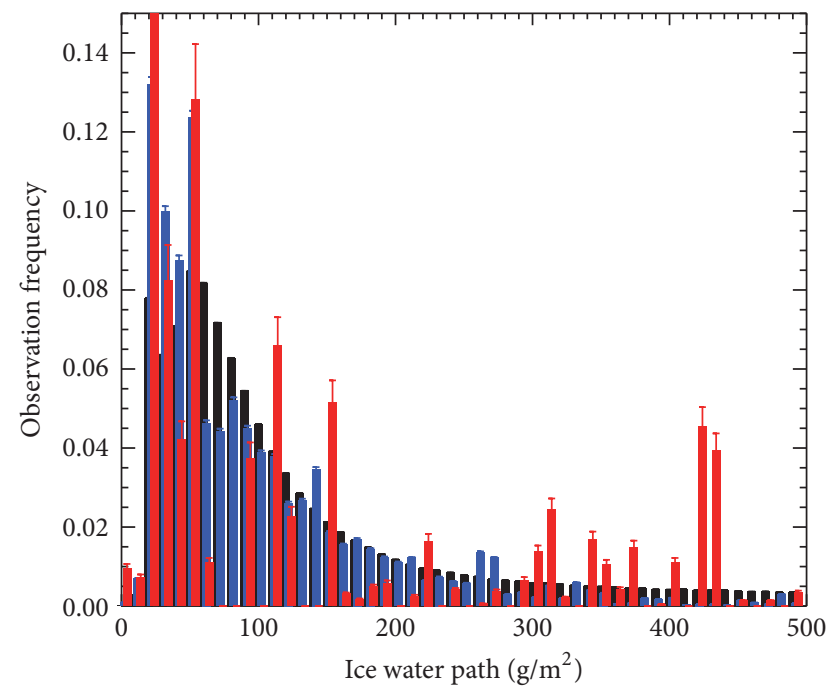

SDev: 106.46

Skew: 1.66

$Q_{50}: 81.63$

$I(H): 4.78$

Mean: 97.36

SDev: 85.66

Skew: 1.76

$Q_{50}: 61.22$

$I(H): 4.43$

Mean: 124.42

SDev: 140.91

Skew: 1.26

$Q_{50}: 40.82$

$I(H): 3.76$

(b)

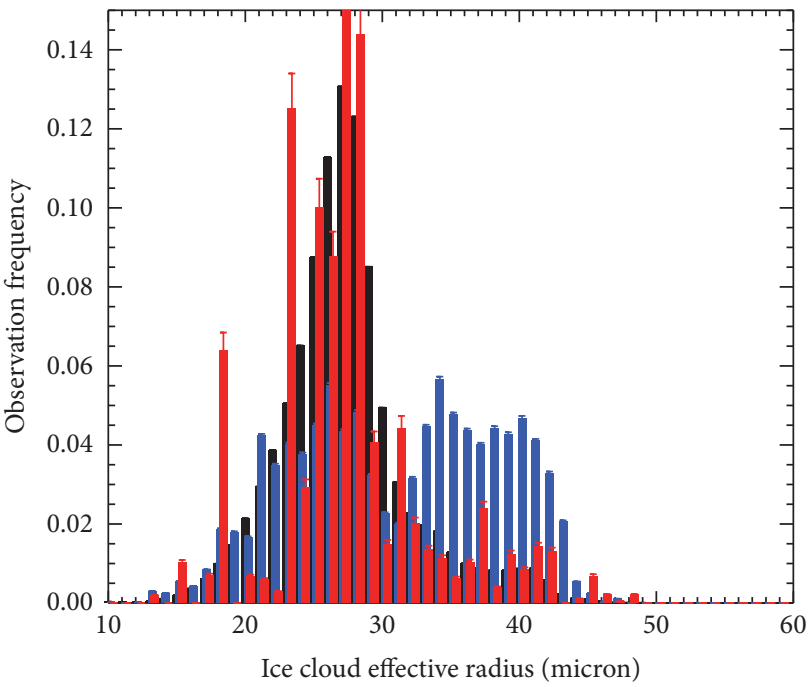

$\begin{array}{lll}\text { Mean: } 27.59 & \text { Mean: } 31.30 & \text { Mean: } 27.61 \\ \text { SDev: } 4.86 & \text { SDev: } 7.56 & \text { SDev: } 5.69 \\ \text { Skew: } 0.72 & \text { Skew: }-0.13 & \text { Skew: } 0.83 \\ Q_{50}: 26.33 & Q_{50}: 31.43 & Q_{50}: 26.33 \\ I(H): 4.16 & I(H): 4.78 & I(H): 3.93\end{array}$

(d)

Figure 8: Observation histograms of ice water path $(a, b)$ and ice cloud effective radius ( $c, d)$ for all cloud observations (a, c) and deep ice clouds only (b, d). Black colour represents pristine background conditions, blue moderate dust loading, and red the high dust loading class.

the average seems comparable, but the changes in standard deviation and skewness also point to a different setting for the dust-cloud relationship. Rain rates in the "high" dust load class have not been analysed as with 28 coincidences the sample size is by far too small for realistic representation in the Bayesian analysis.

\section{Discussion}

In Section 4 we applied the Bayesian analysis method introduced in Section 3 with three dust classes (background, moderate, and high), for five ice cloud and precipitation variables (CTT/IWP, COD, $R_{\text {eff }}, \mathrm{CFC}$, and RR) and with two 
TABLE 3: Mean value of distributions of differences $\Delta H$ for four cloud variables COD, $R_{\mathrm{eff}}$, IWP, and CFC and for RR for moderate and high dust loading subsets limited to the subset of deep ice clouds only. Here, CTT has been used to describe the meteorological state.

\begin{tabular}{|c|c|c|c|c|c|}
\hline & $\langle\Delta H(\mathrm{COD})\rangle$ & $\begin{array}{c}\left\langle\Delta H\left(R_{\mathrm{eff}}\right)\right\rangle \\
{[\mu \mathrm{m}]}\end{array}$ & $\begin{array}{c}\langle\Delta H(\mathrm{IWP})\rangle \\
{\left[\mathrm{g} / \mathrm{m}^{2}\right]}\end{array}$ & $\langle\Delta H(\mathrm{CFC})\rangle$ & $\begin{array}{c}\langle\Delta H(\mathrm{RR})\rangle \\
{[\mathrm{mm} / \mathrm{h}]}\end{array}$ \\
\hline \multicolumn{6}{|c|}{ Moderate dust load $n=19546, n_{\mathrm{RR}>0}=1609$} \\
\hline$\Delta \mu$ & $-0.41 \pm 0.14$ & $+2.40 \pm 0.41$ & $-11.4 \pm 4.3$ & $-0.17 \pm 0.01$ & $-0.48 \pm 0.10$ \\
\hline$\Delta \sigma$ & $-0.20 \pm 0.10$ & $+1.86 \pm 0.29$ & $-7.9 \pm 3.0$ & $-0.02 \pm 0.01$ & $-0.46 \pm 0.07$ \\
\hline$\Delta|\gamma|$ & $+0.11 \pm 0.12$ & $-0.70 \pm 0.12$ & $-0.11 \pm 0.12$ & $+0.75 \pm 0.12$ & $+1.65 \pm 0.43$ \\
\hline$\Delta Q_{50}$ & $-0.21 \pm 0.17$ & $+4.08 \pm 0.52$ & $-10.2 \pm 5.4$ & $-0.22 \pm 0.02$ & $-0.31 \pm 0.13$ \\
\hline$\Delta I$ & $-0.19 \pm 0.66$ & $+0.35 \pm 0.66$ & $-0.19 \pm 0.66$ & $-0.40 \pm 0.66$ & $-1.19 \pm 1.01$ \\
\hline \multicolumn{6}{|c|}{ High dust load $n=295, n_{\mathrm{RR}>0}=28$} \\
\hline$\Delta \mu$ & $+0.20 \pm 1.53$ & $+0.03 \pm 2.33$ & $+14.2 \pm 57.8$ & $+0.02 \pm 0.11$ & N/A \\
\hline$\Delta \sigma$ & $+1.05 \pm 1.08$ & $+0.81 \pm 1.66$ & $+39.1 \pm 41.0$ & $+0.03 \pm 0.08$ & N/A \\
\hline$\Delta|\gamma|$ & $-0.32 \pm 1.01$ & $+0.09 \pm 1.01$ & $-0.65 \pm 1.01$ & $+0.98 \pm 1.01$ & N/A \\
\hline$\Delta Q_{50}$ & $-0.31 \pm 1.92$ & $+0.00 \pm 2.92$ & $-30.6 \pm 72.5$ & $+0.12 \pm 0.15$ & N/A \\
\hline$\Delta I$ & $-0.61 \pm 1.30$ & $-0.23 \pm 1.30$ & $-0.85 \pm 1.30$ & $-1.45 \pm 1.30$ & N/A \\
\hline
\end{tabular}

different constraints for the meteorological state (CTT or IWP). The analysis has been performed with all observations acquired during the Atlantic Ocean hurricane season of 2008 over the basin defined in Section 2. Now we discuss the results of the analysis in the light of the basic assumptions outlined in Section 3.

As the number of independent cloud variables retrieved by IMARS is approximately 2.0-2.5 (Figure 2) over wide swaths of the domain (see discussion above), the results of the dust-cloud-relationship analysis cannot be all independent. Consequently changes in the statistics of one cloud variable due to dust impacts mathematically will be reflected in changes of the other cloud variables as well. But with typically $N_{\text {var }}$ (cloud) $>2$, the approach of using one variable (for example CTT or IWP) as constraining variable and then analysing the other cloud variables (all separately) is quantitatively justified.

When CTT is used for constraining the meteorological state, the cloud optical depth increases on average (in terms of mean and median value) and its distribution becomes wider and less skewed as well. Consequently, the development of (optically) thicker ice clouds seems to be enhanced in the presence of desert dust over the tropical Atlantic Ocean. These results are supported as well by the increase of the PDF information content, which is a measure of the complexity of the Histogram/PDF. Higher values of $I(H)$ describe distributions with more equally distributed values and thus a reduced peak height in the PDF. The advantage of analysing $\Delta I(H)$ instead of, for example, peak height is that it is independent of the number of distribution modes and the same information can be acquired for bior multimodal distributions, such as for effective radius or cloud top temperature. Moreover, $\Delta I(H)$ is a measure for complexity and interdependence [41]. We do not fully follow the interpretation of the "Kullback-Leibler divergence" for multivariate samples here (see discussion in [41]) but rather interpret the information content of the background distribution as the entropy of the undisturbed system. Consequently, any significant change in the magnitude of $I(H)$ relates to decreased interdependence of the dusty and pristine samples following the discussions of Bozdogan [41]. This quantitatively signifies a significant impact of the dusty environment on the distribution statistics of the analysed cloud variable from an information-theoretical point of view.

The increase of COD is accompanied by a decrease in ice cloud effective radius in terms of mean value and median. Also here the standard deviation and the information content are increased, pointing to a widening of the distributions and thus higher variability in ice crystal size in dusty environments. For both, COD and $R_{\text {eff }}$, the magnitudes of the deviations from background conditions increase with dust load; that is, they are higher in the high $\mathrm{AOD}_{\text {dust }}$ class than for moderate dust loading. Ice water path follows the behaviour of cloud optical depth as it is increased on average and shows a wider and less skewed distribution in the vicinity of dust. Consequently, it is (at least in the IMARS data) correlated more strongly with optical depth than with effective radius (see also [26]).

In IMARS, ice cloud effective radius is defined as the radius of a volume-equivalent sphere. For ice clouds the definition of effective radius and its significance for the interpretation of the results is not straightforward [13-15]. As any effective radius definition for nonspherical particles such as ice crystals (or dust particles) is always related to the true particle shape, any changes in retrieved effective radius brought about by interpretation of the radiative signal at the top of atmosphere could as well reflect differences in particle shape and thus ice crystal habit. The exact relationship between effective radius and crystal habit can unfortunately not be resolved from satellite signals. Thus, seeing on average smaller effective radii in dusty environments does not necessarily have to be based on physically smaller crystals in the meaning of less volume but could also signify that the crystal shape might be affected by dust entrainment. Any answer 
of this question has to be left to future laboratory studies, as satellite observations (so far) generally do not provide sufficient information to separate these two effects.

The relationship between dust loading and cloud fractional cover does not yield any consistent results other than that the skewness and complexity of the distribution differs between the background and the two dusty classes, when CTT is used as meteorological constraint. The joint histogram between CFC and CTT features rather high variability of CFC for CTT between $260 \mathrm{~K}$ and $230 \mathrm{~K}$ (not shown). Consequently the assumption of a unique relationship being adequate for constraining the meteorological state is at least questionable in the case of CFC and our analysis can therefore not be used to quantify this relation.

Rain rates are decreased for the moderate dust loading class compared to the pristine background in both, mean and median value. The decrease is accompanied by a decrease in standard deviation at higher skewness. The distribution shows that moderate rain rates become less likely whereas small rain rates increase in frequency while stronger precipitation is not much affected. For the high dust loading class the distribution develops a strong secondary peak at moderate rain rates resulting in only a moderate decrease of mean rain rate while the median in fact increases. However, the sample size for this case is quite small and accordingly this result has low significance.

When the analysis is repeated with constraining the meteorological state by the ice water path, no change in ice cloud optical depth under dusty conditions is observed. Although this appears counterintuitive at first, the explanation lies in the very high correlation between ice water path and optical depth in the IMARS data (see discussion above) so that constraining by IWP effectively also constrains the COD. Effective radius shows the same behaviour as when CTT is used as constraining variable, but the magnitude of the differences is more pronounced in all statistical quantities, while the sign remains the same.

Significant differences occur in the CFC results when using CTT or IWP as constraining cloud variables. If cloud observations are constrained by IWP, CFC significantly decreases in dusty environments for both dust loading classes. The difference to the results for constraining with CTT can be traced back to a much more unique relationship between CFC and IWP than between CFC and CTT in the joint histograms (not shown).

Using IWP as constraining variable has the advantage that this analysis allows analysing statistics of cloud top temperature in dusty environments. Any invigoration of convective activity, which would result in increased COD and IWP, could also lead to increased cloud top heights and thus lower cloud top temperature. In fact, the statistical results support a decrease in average CTT in dusty environments, as a secondary CTT peak around $230 \mathrm{~K}$ develops in the histograms (see Figure 4).

Besides the statistical analysis of all ice clouds observed by IMARS also the subset of deep ice cloud has been analysed (Table 3). The fractions of these clouds in the complete set of all clouds decrease from $16.9 \%$ in the pristine background to $4.3 \%$ at moderate dust levels and $0.6 \%$ in environments with high dust loading. Consequently, the secondary CTT peak cannot be attributed to convective invigoration based on these results; otherwise the fraction of deep ice clouds should be increased in dusty environments unless the fraction of anvil cirrus significantly increases. DeMott et al. [12] argue that in the presence of more ice nuclei (IN, as, for example, dust particles) cirrus clouds should be more extensive, which the IMARS data support as well. Within the deep ice clouds the effective radius is increased for moderate dust loading, whereas COD and IWP decrease as does the standard deviation of their distributions. The decrease of COD and IWP for deep ice clouds is accompanied by a corresponding decrease in fractional cover and rain rate as well. Together with the reduced abundance of these clouds in the set of IMARS observations, these results do not support the theory of widespread convective invigoration in the presence of dust (see also discussion in [16]). Constraining the analysis of deep ice cloud analysis with IWP instead of CTT yields very similar results to those presented in Table 3 (not shown). In that case for the deep ice clouds CTT even increases. As the analysis of all ice clouds shows increases in COD and IWP, this means a thickening of moderately thick cirrus clouds or spreading of anvil cirrus. Which physical process is responsible unfortunately cannot be determined with this method and from satellite data alone.

Analogous to the results presented by Jenkins et al. [16] and obtained from aircraft measurements and satellite imagery, Connolly et al. [17] found evidence from model simulations that deep convective systems can indeed be influenced by aerosol entrainment but that, due to nonlinearities in the effects, there is no very clear relationship. Unfortunately these authors did not take into account aerosol type, that is, the IN suitability of the aerosol. Jenkins et al. [16] describe an invigoration of the convection in the rain band of a tropical cyclone over the Atlantic Ocean basin, but this invigoration is also not evenly distributed over the area of the cyclone.

The results presented in this study favour the conclusions of Connolly et al. [17] that simple correlation or regression analysis is insufficient to explain the full picture of dustice cloud relationships. The analysis of the distribution statistics supports the idea that not only average effects (such as differences in mean or median value) matter for the climate impact of aerosol-cloud-interactions. It is rather the relationship between aerosol loading and cloud statistics, which is of importance. Only the full distribution statistics completely reflect the nonlinearities in aerosol-cloudrelationships described in the literature.

For example, the pronounced bimodality in ice cloud effective radius observations is reduced and the order of peaks is reversed (see Figure 8). This seems to be even stronger in the case of deep ice clouds, despite the smaller sample size and thus higher uncertainty in that case (Figure 8, Table 3). While some of this effect can be attributed to deviations in the cloud top temperature distributions of the different samples, this effect is not as strongly represented in the projected histogram estimates based on the Bayesian method (not shown) and can also be detected when IWP is used as constraining variable. For both dust classes the change of information content 
$\Delta I(H)$ also suggests a reduction in interdependence of the $R_{\text {eff }}$ histograms between background and dusty environment and consequently the presence of a physical process impacting on the effective radius distribution. Whether this is really a change in crystal (and thus cloud ice) volume or if the changing crystal habit is responsible for this effect, unfortunately, cannot be determined from satellite data alone.

With the method outlined in Section 3 for Bayesian CTT (or IWP) adjustment of the analysis of dust effects on (ice) clouds becomes possible. In doing so, the other direction of interaction is ruled out (for example, dust storms caused by convective density currents, e.g., [42, 43]). In such cases no significant deviation should be present in the aerosol case, since the convective cloud development would follow the undisturbed background distribution profile with respect to CTT. However, once aerosol is suspended into the atmosphere it can also affect cloud microphysics of a convective system which is causing dust emission. This makes the method generally applicable over land as well. Although satellite data from other years are available, one single season has been used here for the demonstration of the analysis method in order to avoid interseasonal effects. When interannual variability is concerned, the assumption of spatiotemporal homogeneity required for this approach has to be analysed in far more detail in order to understand the results. The problem of possible effects of interannual (co)variability of dust and clouds over the Atlantic Ocean on the results of statistical analyses will be studied further in the future.

\section{Conclusions}

Infrared satellite observations of desert dust and ice clouds over the tropical Atlantic Ocean during the hurricane season 2008 have been analysed for relationships between dust presence and cloud properties. A Bayesian technique to account for varying meteorological conditions has been used in processing histograms of cloud variables under three subsets stratified by dust AOD. The histogram adaptation for the meteorological state has been done independently with cloud top temperature and ice water path as constraints.

Under the presence of desert dust, ice cloud optical depth and ice water path increase on average while the distributions broaden and get less skewed. At the same time the ice crystal size decreases, again accompanied by broadening and less skewed distributions. For all three cloud variables the histogram complexity indicates a decreasing interdependence between the cloud property frequencies. Thus information theory suggests that, beyond sampling, other (physical) processes result in real changes of the distributions.

Cloud fractional coverage (integrated over the dust correlation length) has been analysed as well but no conclusive results have been obtained for that variable. Precipitation seems to be decreased in the vicinity of dust plumes, but the sample sizes of precipitation observations are significantly smaller than for all ice clouds.

It has been found that the deep ice cloud fraction decreases for dusty cases and that in deep ice clouds the ice amount, as reflected in optical depth and ice water path, decreases at increasing ice crystal sizes. These results are not supportive of the theory of widespread convective invigoration by Saharan dust as for example described by Jenkins et al. [16].

The current study falls short of presenting the full solution to the problems of dust-ice cloud-interaction research. It rather describes a methodology for analysing the relationships with large-scale datasets in a statistical way using a Bayesian approach to analysis of PDFs. It introduces the method with identifying all necessary assumptions and presents first results for a rather homogeneous aerosol-cloud setting. Satellite data which are capable of discriminating desert dust from other aerosols and ice clouds from other cloud phases have been used as input. In order to understand the statistical results presented in this study physically, a combination of analysing satellite and model simulation data with the same method is foreseen for the near future. In such experiments also different pathways of aerosolcloud-interaction can be quantitatively assessed and their quantitative significance in the satellite-based results can be determined.

Different ice nucleating capabilities have been described in the literature for different mineral components of desert dust (e.g., [44, 45]). As IMARS is capable of estimating mineralogical dust composition as well, such laboratory findings can be assessed with these data and the presented method as well by stratification not only by dust loading but also by dust composition. It is clearly evident that for an increase of the complexity of the stratification the sample sizes must be significantly increased as well, as already in the setup presented here sample sizes partly were too small for yielding reliable results. Consequently, in such a future analysis more years have to be included (then methodological assumption (3) has to be given some more consideration). This study is considered to introduce the methodology and present first results for one season. A subsequent study extending the methodology to the full lifespan of the IASI instrument (IASI data currently being processed within the aerosol_cci project of the European Space Agency) will address the multiyear stability and the interannual variability as well. Generally, the method is also capable of being transferred to imaging instruments with smaller FOV sizes such as the Visible Infrared Imaging Radiometer Suite (VIIRS), but a decisive analysis of the information content of retrievals from imaging radiometers has to be performed a priori. Both ways of increasing the sample sizes and thus allowing for more detailed stratification will be pursued in the future. The subsequent study will also revisit assumption (5) of Section 3 and will feature a more detailed inspection of the validity of using cloud top temperature as estimate for the meteorological state and the severeness of the concerns expressed in Section 3. It is envisaged that by also increasing the number of AOD classes a (statistically estimated) derivative of cloud property distribution characteristics with AOD can be determined, which can be tested against model simulations and hopefully will be adequate to improve model performance with respect to the interactions between desert dust and ice clouds. 


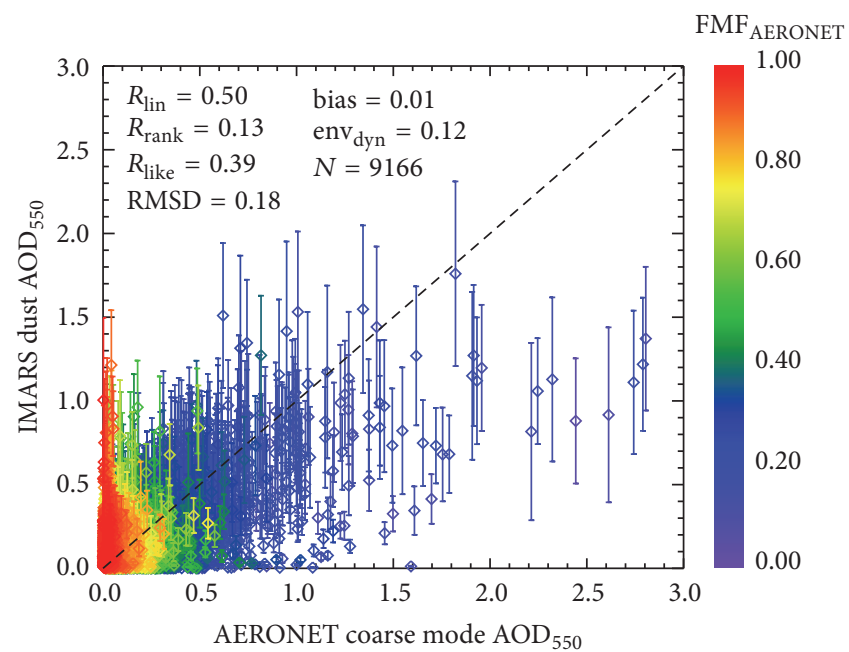

(a)

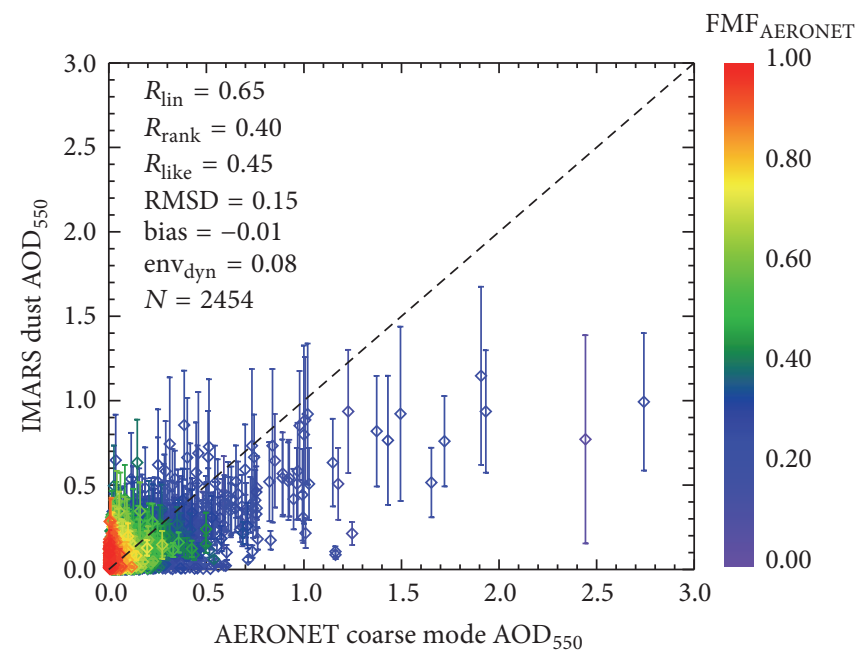

(c)

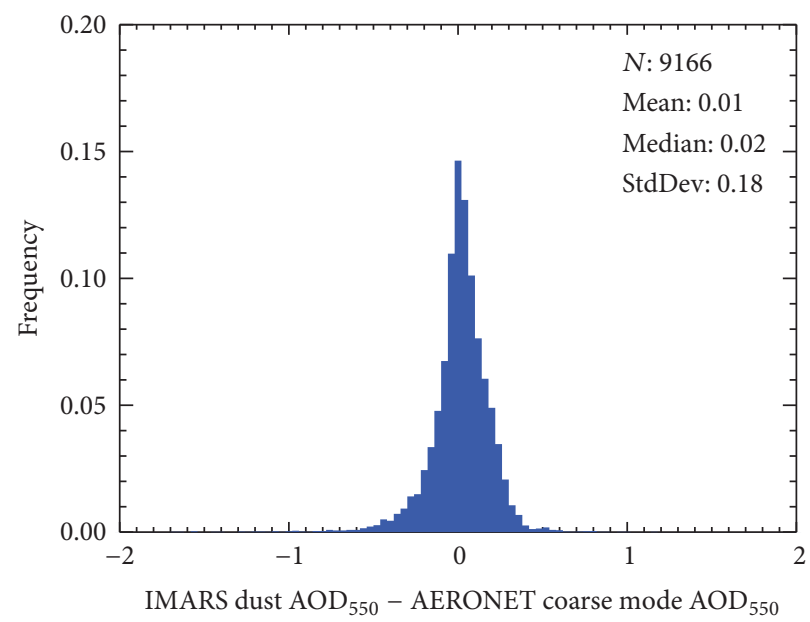

(b)

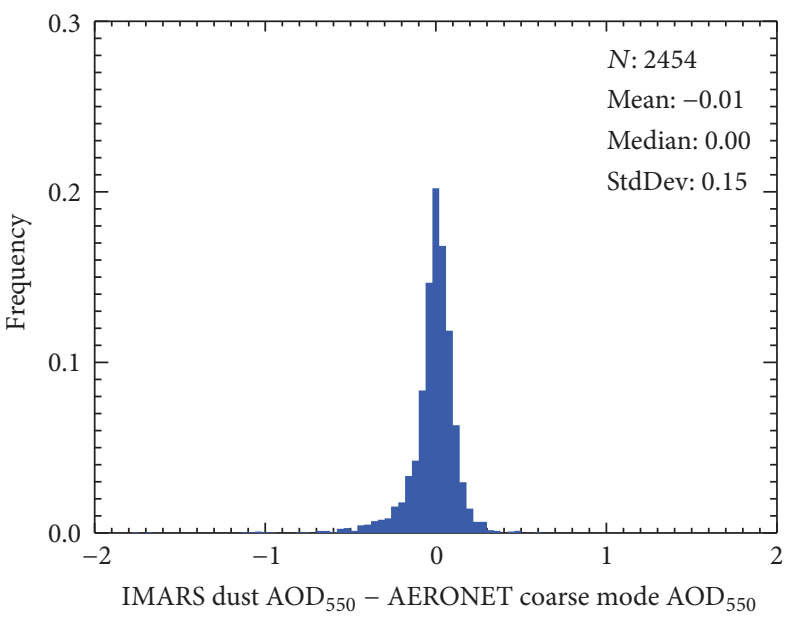

(d)

FIGURE 9: IMARS dust AOD evaluation results against AERONET SDA L2.0 coarse mode AOD in terms of scatter plots (a, c) and deviation histograms (b, d) for IASI observations over land $(a, b)$ and ocean $(c, d)$. Symbol colours represent the SDA retrieved aerosol fine mode fraction (FMF) from AERONET. Observations of 73 AERONET stations for the year 2009 have been used for comparison.

\section{Appendix}

The IMARS scheme has been evaluated against AERONET (AERosol RObotic NETwork, [46]) coarse mode AOD values obtained with the Spectral Deconvolution Algorithm (SDA, [47]). SDA coarse mode Level 2.0 AOD observations from 73 stations throughout Asia, Northern Africa, Europe, and the Atlantic Ocean have been used for evaluation (see [21]). The evaluation has been performed for all available IMARS data of the years 2007-2015. We present in this appendix evaluation results for the latest version (v5.2) of the IMARS algorithm which is used in this study. In this evaluation we separate for the first time for IMARS results over ocean and over land.

Coincidences are aggregated so that for any AERONET station all valid AERONET observations within \pm 1 hour of the overpass of IASI are averaged and their standard deviation is calculated, while the coinciding IASI observations are averaged with Gauss-shaped observation weights:

$$
\varphi=\exp \left(-\left(\frac{\Delta \mathrm{obs}}{75 \mathrm{~km}}\right)^{2}\right) .
$$

$\Delta$ obs signifies the distance between the center of the IASI pixel and the station. Consequently, IASI observations closer to a station have higher weight in the averaging than those further away.

We use different evaluation metrics including two correlation estimates: $R_{\operatorname{lin}}$ is the classical Pearson correlation and $R_{\text {rank }}$ is the Spearman rank correlation $\left(R_{\text {like }}\right.$ is a PDF based likelihood correlation not discussed here; see [22] for details). RMSD represents the traditional root-meansquared difference and the bias is the average deviation. $e v_{\text {dyn }}$ describes the width of the dynamic envelope around 
TABLE 4: IMARS v5.2 evaluation statistics for 2007-2015 against AERONET SDA L2.0 observations for all, land only, and ocean only IASI pixels.

\begin{tabular}{lccc}
\hline & All & Land & Ocean \\
\hline$R_{\text {lin }}$ & 0.51 & 0.50 & 0.65 \\
$R_{\text {rank }}$ & 0.13 & 0.13 & 0.40 \\
RMSD & 0.18 & 0.18 & 0.15 \\
bias & 0.01 & 0.01 & -0.01 \\
env $_{\text {dyn }}$ & 0.12 & 0.12 & 0.08 \\
$N$ & 9459 & 9166 & 2454 \\
\hline
\end{tabular}

the identity, in which $e^{-1}$ of the coincidences are found (as introduced in [21]). $N$ is the number of coincidences.

Evaluation metrics have been determined for a range of subsets in order to estimate the impact of quality filtering, size and composition retrieval, and surface treatment on the product quality (not shown here). Table 4 lists overall validation statistics. "All" means all available IMARS observations have been used. For "Land" only IASI FOVs over land have been included into the aggregation, whereas for "Ocean" only FOVs over ocean are included. Results for land and ocean observations are depicted separately as scatter plots and deviation histograms in Figure 9. Symbol colour in the scatter plot moreover indicates the fine mode fraction retrieved from the AERONET observations by the SDA algorithm. The scatterplot RMSD and the histogram standard deviation (StdDev) are mathematically equivalent. In the histograms moreover the median difference between AERONET and IMARS is presented. The validation in Figure 9 clearly shows the higher quality of IMARS retrievals over ocean as compared to over land. Furthermore, the evaluation over both land and ocean shows the known tendency of AOD underestimation by IMARS for high dust loadings $\left(\mathrm{AOD}_{\text {dust }}\right.$ above 1) which is already described in Klüser et al. [19], Banks et al. [24], and Klüser et al. [21]. This effect seems to be more pronounced over ocean, where IMARS AOD acquires maximum values of about 1 also at much higher AERONET AOD than over land.

\section{Conflicts of Interest}

The authors declare that they have no conflicts of interest.

\section{Acknowledgments}

The authors acknowledge funding within the DLR project "KliSAW" for the development and implementation of the Bayesian analysis method for aerosol-cloud-interactions. The development and provision of correlation lengths result from the European Collaborative Project "DNICast," funded within the 7th Framework Programme (FP7) under Grant no. 608623. They are thankful to EUMETSAT and the EUMETSAT Data Centre (UMARF) for providing the IASI observations from METOP. IMARS data have been processed within and provided by the Aerosol_cci project of the European Space Agency ESA (Contract no. 4000109874/14/INB). They are thankful to NASA and the Goddard Earth
Sciences Data and Information Services Center for provision of TRMM 3B42 rainfall estimates.

\section{References}

[1] M. D. King, Y. J. Kaufman, D. Tanré, and T. Nakajima, "Remote sensing of tropospheric aerosols from space: past, present, and future," Bulletin of the American Meteorological Society, vol. 80, no. 11, pp. 2229-2259, 1999.

[2] D. Rosenfeld, Y. Rudich, and R. Lahav, "Desert dust suppressing precipitation: a possible desertification feedback loop," Proceedings of the National Academy of Sciences of the United States of America, vol. 98, no. 11, pp. 5975-5980, 2001.

[3] Y. J. Kaufman, D. Tanré, and O. Boucher, "A satellite view of aerosols in the climate system," Nature, vol. 419, no. 6903, pp. 215-223, 2002.

[4] V. Ramanathan, P. J. Crutzen, J. T. Kiehl, and D. Rosenfeld, "Atmosphere: aerosols, climate, and the hydrological cycle," Science, vol. 294, no. 5549, pp. 2119-2124, 2001.

[5] B. Stevens and G. Feingold, "Untangling aerosol effects on clouds and precipitation in a buffered system," Nature, vol. 461, no. 7264, pp. 607-613, 2009.

[6] J. Perlwitz and R. L. Miller, "Cloud cover increase with increasing aerosol absorptivity: a counterexample to the conventional semidirect aerosol effect," Journal of Geophysical Research Atmospheres, vol. 115, no. D8, Article ID D08203, 2010.

[7] K. S. Carslaw, O. Boucher, D. V. Spracklen et al., "A review of natural aerosol interactions and feedbacks within the Earth system," Atmospheric Chemistry and Physics, vol. 10, no. 4, pp. 1701-1737, 2010.

[8] U. Lohmann and J. Feichter, "Global indirect aerosol effects: a review," Atmospheric Chemistry and Physics, vol. 5, no. 3, pp. 715-737, 2005.

[9] I. Langmuir, "The production of rain by a chain reaction in cumulus clouds at temperatures above freezing," Journal of Meteorology, vol. 5, no. 5, pp. 175-192, 1948.

[10] S. L. Broadley, B. J. Murray, R. J. Herbert et al., "Immersion mode heterogeneous ice nucleation by an illite rich powder representative of atmospheric mineral dust," Atmospheric Chemistry and Physics, vol. 12, no. 1, pp. 287-307, 2012.

[11] O. M. Doherty and A. T. Evan, "Identification of a new duststratocumulus indirect effect over the tropical North Atlantic," Geophysical Research Letters, vol. 41, no. 19, pp. 6935-6942, 2014.

[12] P. J. DeMott, A. J. Prenni, X. Liu et al., "Predicting global atmospheric ice nuclei distributions and their impacts on climate," Proceedings of the National Academy of Sciences of the United States of America, vol. 107, no. 25, pp. 11217-11222, 2010.

[13] G. M. McFarquhar and A. J. Heymsfield, "The definition and significance of an effective radius for ice clouds," Journal of the Atmospheric Sciences, vol. 55, no. 11, pp. 2039-2052, 1998.

[14] D. L. Mitchell, "Effective diameter in radiation transfer: general definition, applications, and limitations," Journal of the Atmospheric Sciences, vol. 59, no. 15, pp. 2330-2346, 2002.

[15] D. L. Mitchell, R. P. Lawson, and B. Baker, "Understanding effective diameter and its application to terrestrial radiation in ice clouds," Atmospheric Chemistry and Physics, vol. 11, no. 7, pp. 3417-3429, 2011.

[16] G. S. Jenkins, A. S. Pratt, and A. Heymsfield, "Possible linkages between Saharan dust and tropical cyclone rain band invigoration in the eastern Atlantic during NAMMA-06," Geophysical Research Letters, vol. 35, no. 8, Article ID L08815, 2008. 
[17] P. J. Connolly, G. Vaughan, P. T. May et al., "Can aerosols influence deep tropical convection? Aerosol indirect effects in the Hector island thunderstorm," Quarterly Journal of the Royal Meteorological Society, vol. 139, no. 677, pp. 2190-2208, 2013.

[18] K. Emanuel, “Tropical cyclones," Annual Review of Earth and Planetary Sciences, vol. 31, no. 1, pp. 75-104, 2003.

[19] L. Klüser, D. Martynenko, and T. Holzer-Popp, “Thermal infrared remote sensing of mineral dust over land and ocean: a spectral SVD based retrieval approach for IASI," Atmospheric Measurement Techniques, vol. 4, no. 5, pp. 757-773, 2011.

[20] L. Klüser, P. Kleiber, T. Holzer-Popp, and V. H. Grassian, "Desert dust observation from space-Application of measured mineral component infrared extinction spectra," Atmospheric Environment, vol. 54, pp. 419-427, 2012.

[21] L. Klüser, J. R. Banks, D. Martynenko, C. Bergemann, H. E. Brindley, and T. Holzer-Popp, "Information content of spaceborne hyperspectral infrared observations with respect to mineral dust properties," Remote Sensing of Environment, vol. 156, pp. 294-309, 2015.

[22] L. Klüser, "ESA Climate Change Initiative aerosol_cci-Infrared Mineral Aerosol Retrieval Scheme (IMARS) Algorithm Theoretical Basis Document (ATBD)," 2016, Version 2.0, http:// www.esa-aerosol-cci.org/.

[23] L. Klüser, C. Di Biagio, P. D. Kleiber, P. Formenti, and V. H. Grassian, "Optical properties of non-spherical desert dust particles in the terrestrial infrared-An asymptotic approximation approach," Journal of Quantitative Spectroscopy and Radiative Transfer, vol. 178, pp. 209-223, 2016.

[24] J. R. Banks, H. E. Brindley, C. Flamant et al., "Intercomparison of satellite dust retrieval products over the west African Sahara during the Fennec campaign in June 2011," Remote Sensing of Environment, vol. 136, pp. 99-116, 2013.

[25] J. M. Comstock, R. D’Entremont, D. De Slover et al., “An intercomparison of microphysical retrieval algorithms for uppertropospheric ice clouds," Bulletin of the American Meteorological Society, vol. 88, no. 2, pp. 191-204, 2007.

[26] A. J. Heymsfield, S. Matrosov, and B. Baum, "Ice water pathoptical depth relationships for cirrus and deep stratiform ice cloud layers," Journal of Applied Meteorology, vol. 42, no. 10, pp. 1369-1390, 2003.

[27] C. E. Shannon, The Mathematical Theory of Communication, The University of Illinois Press, Urbana, Ill, USA, 1949.

[28] A. Ben-Naim, "Entropy, Shannon's measure of information and Boltzmann's H-theorem," Entropy. An International and Interdisciplinary Journal of Entropy and Information Studies, vol. 19, no. 2, Paper No. 48, 18 pages, 2017.

[29] C. E. Shannon, "Communication in the presence of noise," Proceedings of the IEEE, vol. 86, no. 2, pp. 447-457, 1998.

[30] G. J. Huffman, R. F. Adler, D. T. Bolvin et al., "The TRMM Multisatellite Precipitation Analysis (TMPA): quasi-global, multiyear, combined-sensor precipitation estimates at fine scales," Journal of Hydrometeorology, vol. 8, no. 1, pp. 38-55, 2007.

[31] K. Schepanski, L. Klüser, B. Heinold, and I. Tegen, "Spatial and temporal correlation length as a measure for the stationarity of atmospheric dust aerosol distribution," Atmospheric Environment, vol. 122, pp. 10-21, 2015.

[32] J. Chen and D. Lamb, "Simulation of cloud microphysical and chemical processes using a multicomponent framework. Part I: description of the microphysical model," Journal of the Atmospheric Sciences, vol. 51, no. 18, pp. 2613-2630, 1994.
[33] Y. Rudich, A. Sagi, and D. Rosenfeld, "Influence of the Kuwait oil fires plume (1991) on the microphysical development of clouds," Journal of Geophysical Research, vol. 108, no. D15, 2003.

[34] T. Yuan, L. A. Remer, K. E. Pickering, and H. Yu, “Observational evidence of aerosol enhancement of lightning activity and convective invigoration," Geophysical Research Letters, vol. 38, no. $4,2011$.

[35] M. W. Christensen, K. Suzuki, B. Zambri, and G. L. Stephens, "Ship track observations of a reduced shortwave aerosol indirect effect in mixed-phase clouds," Geophysical Research Letters, vol. 41, no. 19, pp. 6970-6977, 2014.

[36] A. N. Kolmogorov, "Logical basis for information theory and probability theory," IEEE Transactions on Information Theory, vol. 14, no. 5, pp. 662-664, 1968.

[37] T. Bayes, "An essay towards solving a problem in the doctrine of chances," Philosophical Transactions of the Royal Society of London, vol. 53, pp. 370-418, 1763.

[38] J. Earman, “Bayes' bayesianism," Studies in History and Philosophy of Science, vol. 21, no. 3, pp. 351-370, 1990.

[39] R. Blanc, J.-P. Da Costa, Y. Stitou, P. Baylou, and C. Germain, "Assessment of texture stationarity using the asymptotic behavior of the empirical mean and variance," IEEE Transactions on Image Processing, vol. 17, no. 9, pp. 1481-1490, 2008.

[40] M. Perron and P. Sura, "Climatology of non-gaussian atmospheric statistics," Journal of Climate, vol. 26, no. 3, pp. 10631083, 2013.

[41] H. Bozdogan, "Akaike's information criterion and recent developments in information complexity," Journal of Mathematical Psychology, vol. 44, no. 1, pp. 62-91, 2000.

[42] S. D. Miller, A. P. Kuciauskas, M. Liu et al., "Haboob dust storms of the southern Arabian Peninsula," Journal of Geophysical Research Atmospheres, vol. 113, no. 1, Article ID D01202, 2008.

[43] P. Knippertz and M. C. Todd, "The central west Saharan dust hot spot and its relation to African easterly waves and extratropical disturbances," Journal of Geophysical Research Atmospheres, vol. 115, no. 12, Article ID D12117, 2010.

[44] F. Zimmermann, S. Weinbruch, L. Schütz et al., "Ice nucleation properties of the most abundant mineral dust phases," Journal of Geophysical Research Atmospheres, vol. 113, no. 23, Article ID D23204, 2008.

[45] A. Welti, F. Lüönd, O. Stetzer, and U. Lohmann, "Influence of particle size on the ice nucleating ability of mineral dusts," Atmospheric Chemistry and Physics, vol. 9, no. 18, pp. 6705-6715, 2009.

[46] B. N. Holben, T. F. Eck, I. Slutsker et al., "AERONET-a federated instrument network and data archive for aerosol characterization," Remote Sensing of Environment, vol. 66, no. 1, pp. 1-16, 1998.

[47] N. T. O’Neill, T. F. Ecki, A. Smirnov, B. N. Holben, and S. Thulasiraman, "Spectral discrimination of coarse and fine mode optical depth," Journal of Geophysical Research, vol. 108, no. D17, 2003. 

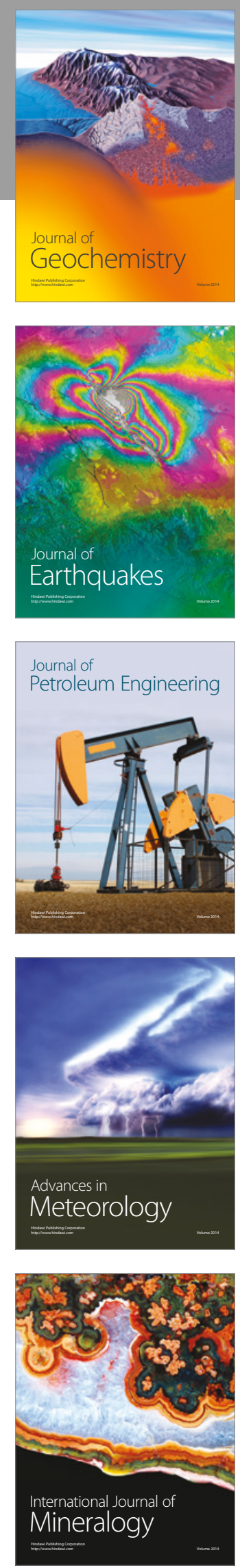
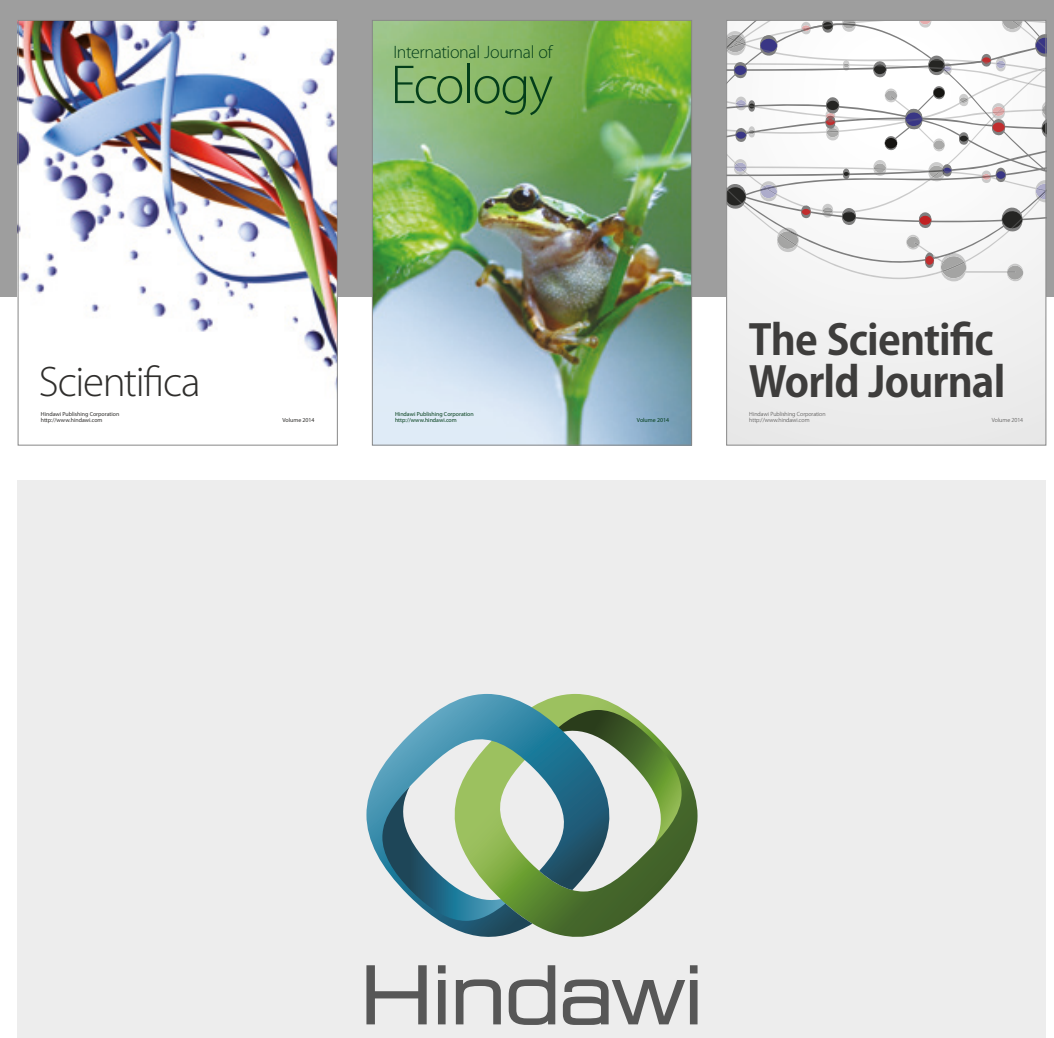

Submit your manuscripts at

https://www.hindawi.com
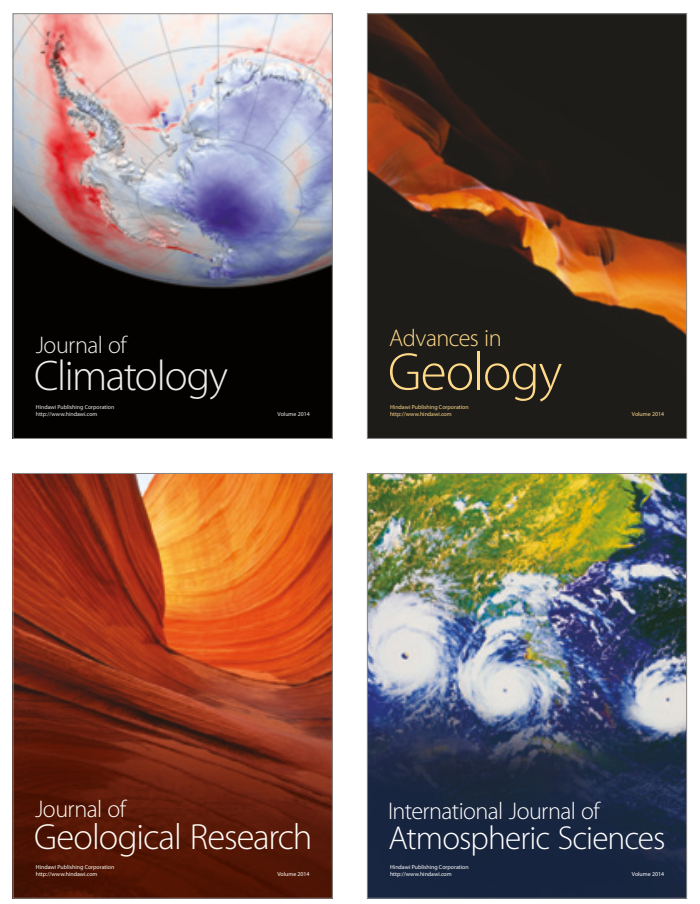

The Scientific

World Journal
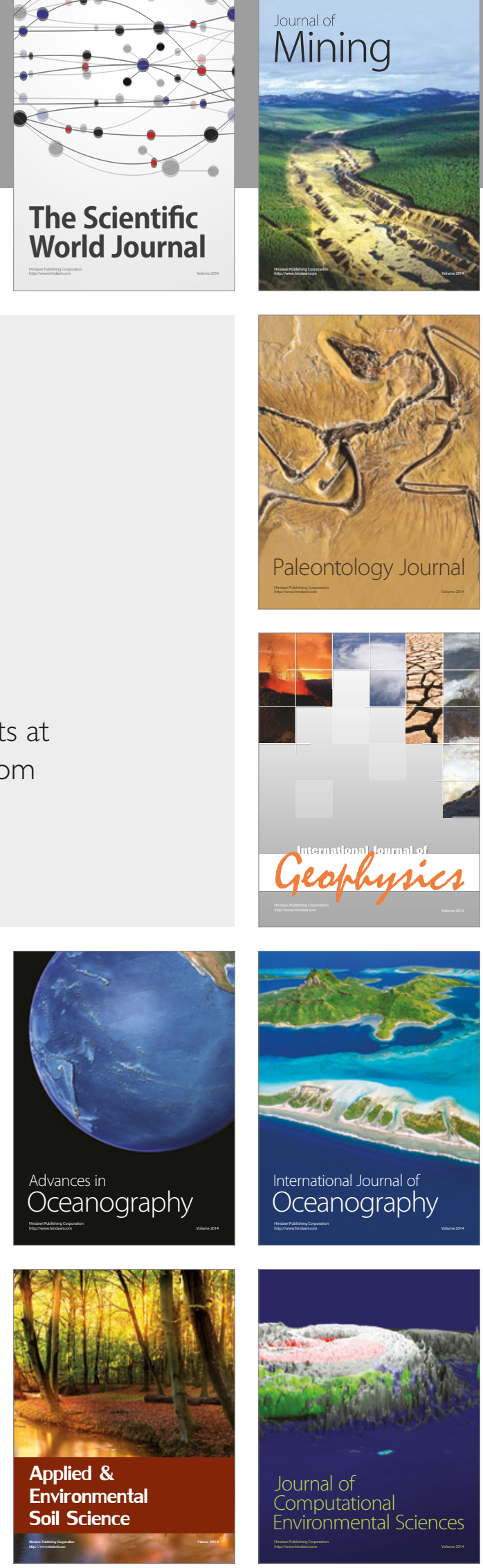